http://economix.fr

\title{
The Private Value of Plant Variety Protection and the Impact of Exemption Rules
}

Document de Travail

Working Paper 2016-07
Marc Baudry Adrien Hervouet

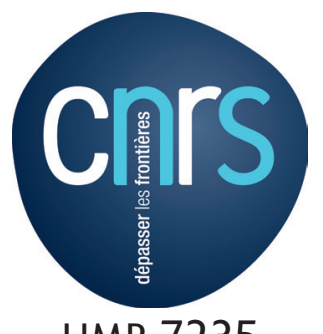

UMR 7235
Université de Paris Ouest Nanterre La Défense (bâtiment G)

200, Avenue de la République 92001 NANTERRE CEDEX université

Paris Ouest

Nanterre La Défense 


\title{
The Private Value of Plant Variety Protection and the Impact of Exemption Rules
}

\author{
Baudry Marc ${ }^{* \dagger} \quad$ Hervouet Adrien ${ }^{\ddagger}$
}

February 2, 2016

\begin{abstract}
Plant Breeders Rights (PBRs) are sui generis IPRs intended to promote plant variety creation. Two characteristics distinguish PBRs from patents: the research and the farmers' exemptions. This article attempts to assess the impact of these exemption rules on the private value of PBRs. For this purpose, a microeconometric model of PBRs renewals is developed and estimated. This model extends previous models of patents renewals by allowing the use of PBRs-specific variables. It is argued that simple tests on the coefficients associated to key PBRs-specific variables can provide insights into the impact of the two exemption rules. Implementation to PBRs in France over the period 1973-2011 for six major crops suggests that neither the farmers' exemption nor the research exemption have a clear cut effect on the private value of PBRs. We conclude that there is no evidence to argue in favor of a reform of PBRs.
\end{abstract}

Key words: IPRs, Inventors' exemption, Farmers' exemption, Plant variety creation, Renewals

JEL classifications: O34, Q16, C41

*Université de Paris Ouest Nanterre la Défense, EconomiX (UMR CNRS 7235), 200 Avenue de la République, 92001 Nanterre Cedex, France

${ }^{\dagger}$ Climate Economics Chair, Palais Brongniart, 4th floor, 28 place de la Bourse, 75002 Paris, France

$\ddagger$ Université Grenoble Alpes, UMR GAEL INRA, CS 40700, 38058 Grenoble Cedex 9, France, Tel.: +33476 8254 12, adrien.hervouet@grenoble.inra.fr 


\section{Introduction}

A noticeable factor of agricultural productivity growth is innovation in plant variety creation, also known as plant breeding (Evenson, 2001). Like any other innovative activity, plant breeding is subject to an appropriability problem of return on $R \& D$ investment by investors. Consequently, the socially detrimental disconnection between private and social returns on R\&D, highlighted by Arrow (1962) and Dasgupta and Stiglitz (1980), also appears in the seed sector. Moreover, plant variety creation relies intrinsically on incremental innovation. Therefore, while some countries consider that patents are relevant to provide proper incentives to invest in plant variety creation, other countries have rather established sui generis Intellectual Property Rights (IPRs), namely Plant Breeders' Rights (PBRs). A PBR gives exclusive rights on production/reproduction and commercialization that relate to exclusive rights given by a patent. Nevertheless, PBRs differ from patents due to several exemption rules.

The first one is research exemption which allows any innovator to use protected varieties to create a new variety without the agreement of the holder. A much more narrow and restrictive research exemption may also exist for patents, not only in favor of public labs but also in favor of private labs.11 In the case of PBRs, research exemption is the rule, not the exception. Contrary to open research and open source software, research exemption goes with IPRs and does not preclude them. The second exemption is farmers' privilege. It is specific to the seed sector and enables farmers to use farm-saved seeds (see Lesser, 2000; Louwaars et al., 2005, for a more detailed comparison between PBRs and patents). Both exemptions negatively affect the private returns on $R \& D$ in counterpart of higher expected social returns. The optimal choice of the regulator between patents and PBRs thus crucially depends on the significance and the magnitude of the loss of private returns on R\&D induced by the two exemption rules.

\footnotetext{
${ }^{1}$ For instance, in the US law the Hatch-Waxman exemption is a kind of research exemption that applies to generic manufacturers of drugs for a limited term before the patent's statutory expiry.
} 
The paper more specifically develops a test to assess whether the private value of IPRs on plant variety creation in countries that have preferred PBRs to patents is significantly impacted by the two exemption rules. If the private value of PBRs is not found to be significantly affected by the two exemption rules, we can conclude that the choice of PBRs is optimal. This eventuality can more specifically occur if plant variety differentiation is sufficiently high to make innovators insensitive to innovation by competitors (and thus to the research exemption) and not very sensitive to variations of the market size (and thus to the farmers' exemption). Conversely, if the private value of PBRs is found to be significantly affected by at least one of the two exemption rules, then the loss of private return on $\mathrm{R} \& \mathrm{D}$ has to be balanced with social returns and a reform of the IP regime could make sense.

How large are the social returns from variety creation has been studied by several authors but is still controversial. Alston and Venner (2002), for instance, examine the effect of PBRs on the agricultural productivity growth for wheat in the U.S. and find no evidence of a positive impact. Other authors such as Carew and Devadoss (2003) for canola in Canada or Thomson (2015) for wheat in Australia also conclude that there is no evidence of a positive impact. In an other contribution, Diez (2002) finds a positive effect of PBRs on private research. The aim of this paper is rather to assess by how much private incentives to invest in plant variety creation may be affected by the two exemption rules of PBRs. Indeed, little is known about this key element of the discussion on merits of PBRs compared to patents.

For this purpose, the paper builds on the literature that deals with the use of patent statistics to value patents (see Griliches, 1990, for a review). PBRs statistics are, to some extent, similar to patent statistics and allow an analysis that will focus on the assessment of the value of PBRs. Indeed, as for a patent, a breeder has to pay an annual renewal fee to keep his PBR in force (excepted in the U.S.). If the breeder fails to pay, the right is permanently withdrawn and falls into the public domain. Assuming that a breeder is a rational economic agent, he will stop to pay the renewal 
fee if it exceeds the value obtained from keeping the PBR for an additional year. The method for assessing the value of PBRs presented in this article is thus based on data on renewal fee schedules and on the information revealed by breeders' decisions on whether to keep their PBRs in force or not. One of the first attempt to assess the value of patents was Pakes and Schankerman (1984) with a deterministic model of renewal decisions. Their contribution focuses on five European countries before the second world war. The main result is that the somewhat arbitrarily fixed rate of decay used in the literature for the rent that accrues from the detention of a patent is far too small compared to their estimation. Schankerman and Pakes 1985, 1986) use post second world war patent statistics for three European countries and obtain a similar result (e.g. a rate of decay included between 0.07 and 0.25 ). Moreover, they find that the distribution of patent values is sharply skewed. Indeed, a noticeable part of the value is concentrated in the right tail of the distribution. Schankerman (1998) ameliorates the assessment of patent value by distinguishing different technology fields but his work still relies on the key assumption of a decreasing rent, net of the renewal fee. This assumption is relaxed by Pakes (1986), Lanjouw et al. (1998) or Baudry and Dumont (2006), who develop a real option approach to renewal decisions where the time path of the rent is stochastic. Nevertheless, this approach more or less confirms the idea that the probability of an increase of the rent is unlikely. To our knowledge, Srinivasan (2003, 2012) is the first to adopt the model developed by Schankerman and Pakes (1986) to estimate the value of PBRs. He obtains results similar to those from the literature on patents value regarding the depreciation rate and the skewness of the distribution of values. An alternative approach is proposed by Lesser (1994) who suggests to estimate the impact of PBRs with a hedonic price method. He concludes that American PBRs have a very limited value. His approach admits some similarities with alternative methods, such as Tobin's Q methods (see Bessen, 2009; Bloom and Van Reenen, 2002, Hall et al., 2005, for example), which are used to estimate the value of patents. A pitfall of all these works is that they do not account for observed heterogeneity at the microeconomic level. We argue that it is an important drawback if one intends to assess the loss of value generated by 
farmers' exemption and research exemption.

Farmers' exemption distinguishes PBRs from patents and implies that only a fraction of the potential market for commercialized seeds can be captured by breeders. A contrario, a counterfactual removal of farmers' exemption is expected to influence the value of PBRs, as if the potential market had increased independently of an increase of the profitability of the crop. In order to capture such an impact, a modeling of PBRs renewal decisions that accounts for the influence of cohortspecific variables is required. The impact of research exemption cannot be assessed as directly as that of the farmers' exemption. We are inclined to think that research exemption increases the rate of decay of the rent that accrues from PBRs, due to more competitors creating new varieties around the existing ones. Research exemption thus results in an accelerated downgrading of varieties protected by existing PBRs. Consequently, it is crucial that the modeling of PBRs be consistent with the introduction of PBRs-specific variables, more specifically to variables related to the portfolio of PBRs on the same crop hold by competitors, in order to deal with research exemption. Besides the effect of exemption rules, it is also expected that other factors can impact the value of PBRs at the microeconomic level. More specifically, it is expected that the degree of specialization and of product differentiation influence the value of a given PBR. Said in other words, it is expected that the portfolio of PBRs on the same crop that a breeder holds affects the value of the PBRs embedded in this portfolio. Disregarding such a source of microlevel observed heterogeneity can bias the estimates of the rate of decay of the rent and of the impact of the profitability of the crop. By contrast with Srinivasan 2003, 2012), we therefore rather follow Barney (2002), Bessen (2008) and Baudry and Dumont (2012) who adapt the model of Schankerman and Pakes (1986) in order to incorporate microeconomic variables as a source of observed heterogeneity.

Section 2 presents a modeling of renewal decision that is suitable for the introduction of not only cohort-specific but also PBR-specific variables. A discrete time 
duration model of PBRs is derived from the microeconomic modeling. Section 3 presents PBRs statistics and estimation results for PBRs granted in France from 1973 to 2011 for six major crops. It also discusses a test of what could be the consequence of suppressing exemption rules on the simulated values of PBRs. Section 4 concludes that farmers' exemption matters more than inventors' exemption for the value of PBRs. 


\section{Model Setting}

Renewal data are a corner stone to assess the value of Intellectual Property Rights. Rational agents will decide to renew their IPR if and only if the value they expect from renewing it exceeds the renewal cost. Schankerman and Pakes (1986) have shown that, under reasonable conditions regarding the dynamics of the rent and the dynamics of renewal fees, the optimal renewal decision resumes to a simple comparison between the current rent and the current renewal fee. Consequently, data on renewal decisions reveal information about the value of rents and in fine about the private value of IPRs. This key idea is developed in the first subsection. The second subsection presents the econometric strategy used to estimate the model on microlevel data.

\subsection{The value maximization problem}

Like patents, PBRs confer to their holder an exclusivity right on the commercial opportunities that arise from the protected variety. The rent that accrues from this exclusivity right is denoted by $R_{i, t}$ where $i$ denotes the new variety protected by the $\mathrm{PBR}$ and $t$ is the age of the PBR expressed in years. A firm $f$ can hold several PBRs on different varieties of a same crop. We denote by $P_{f}=\left\{1, \ldots, N_{f}\right\}$ its portfolio of PBRs on $N_{f}$ varieties of the same crop and we posit that the rents associated to these different PBRs are interdependent, a configuration that typically arises in the presence of product differentiation, both horizontal and vertical. The rent from PBR $i$ at date $t$ then comprises two elements. The first element is the profit flow that accrues from the commercialization of variety $i$. The second element is the loss (or gain) in the profit flows generated by PBRs on other varieties of the same crop hold by the same firm (i.e. the variation of these profit flows compared to the portfolio $\left.P_{f}-\{i\}\right)$. These two elements depend on the composition of the portfolios $P_{f}$ and $\bar{P}_{f}$ of PBRs on varieties of the same crop hold respectively by the firm $f$ 
and by its competitors ${ }^{2} R_{i, t}\left(P_{f}, \bar{P}_{f}\right)$ is generally not observed by others than the PBR holder and, in particular, is unknown to the econometrician. More precisely, $R_{i, t}\left(P_{f}, \bar{P}_{f}\right)$ stands for the flow of revenues net of the unobserved costs of keeping the PBR alive. From year to year, the PBR holder has to pay a renewal fee $C_{i, t}$, which is the observed component of the cost of renewing the PBR. Failure to pay the renewal fee implies the irreversible loss of the PBR. As will be stressed latter on, the renewal fee may vary with the age of the PBR. It may also change from one cohort of PBRs to another one, due to administrative decisions. This is reflected by the two index $i$ and $t$ of the renewal fee. The loss of the PBR results in the total dissipation of the associated rent. Renewing the PBR is not feasible beyond the statutory lifespan $T$. For the purpose of our econometric analysis, we are interested in the decision of a firm $f$ to renew or to withdraw a given PBR conditional on the composition of its portfolio and on that of its competitors. Accordingly, the aim of the PBR holder is to determine the optimal decision rule that maximizes the value of the PBR defined as the expected and discounted sum of the rents minus the renewal fees at the different ages of the PBR. The problem that the PBR holder is facing is then formally identical to the following optimal stopping program:

$$
V_{i}\left(P_{f}, \bar{P}_{f}\right)=\operatorname{Max}_{\tau_{i} \in\{1, . ., T\}} E_{0}\left[\sum_{t=0}^{\tau_{i}} \frac{R_{i, t}\left(P_{f}, \bar{P}_{f}\right)-C_{i, t}}{\rho_{i, t}}\right]
$$

where

$$
\rho_{i, t}= \begin{cases}1 & \text { for } t=0 \\ \prod_{s=1}^{t}\left(1+r_{i, s}\right) & \text { for } t>0\end{cases}
$$

is the discount factor for date $t$ and $r_{i, s}$ is the interest rate prevailing at age $s$ for PBR $i$. We assume that the PBR holder is risk neutral so that the interest rate of government bonds can be used for $r_{i, s}$. The time path of the rent is unknown to the PBR holder at age $t=0$ but the PBR holder is assumed to know the stochastic

\footnotetext{
${ }^{2}$ We assume that the profit flows are independent from PBRs on varieties of other crops. Throughout the article, the concept of portfolio thus refers to a set of PBRs on different varieties of a same crop hold by a same firm, not to the wider set of PBRs on all crops hold by a same firm.
} 
process that generates the rent and to observe the realizations of the rent from date to date as time goes. $E_{t}$ stands for the operator of mathematical expectation conditional on the information at age $t$. From an econometric perspective, an endogeneity issue arises. Indeed, other PBRs within portfolio $P_{f}$ are also renewed according to an optimal stopping program similar to (1), so that the renewal decision for each PBR actually depends on the renewal versus withdrawal decision of the other PBRs that belongs to a same portfolio. This endogeneity issue will be addressed latter in the article. We are ultimately interested in assessing how the private value $V_{i}$ of PBR $i$ would be impacted by a removal of farmers' exemption and a removal of inventors' exemption. For this purpose, we need to characterize the dynamics of the rent $R_{i, t}$ and to determine the optimal stopping rule $\tau_{i}^{*}$.

\subsection{Assumptions to obtain a simple decision rule}

Solving optimal stopping rule programs like (1) is generally not straightforward and requires the use of stochastic calculus. Pakes (1986) has been the first to develop a real option approach to this problem in the context of patent renewal decisions. In parallel, Schankerman and Pakes (1986) have proposed an alternative to the real option approach that relies on the fact that the rent and the renewal fees generally satisfy a convenient property discussed below.

In most cases, renewal fees for PBRs, like those for patents, increase with the age of the Intellectual Property Right (IPR). Scotchmer (1999) and Cornelli and Schankerman (1999) develop arguments, based on information asymmetries, for public authorities in charge of granting patents and/or PBRs to implement a profile of renewal fees that is increasing and convex with the age of IPRs. Together with the assumption that the rent decreases with the age of the IPR, due to competitors inventing around the protected invention, a phenomenon referred to as depreciation, there is a single crossing property of the time path of the rent with the time path of renewal fees. In other words, the holder of the IPR knows that once the rent is less than the renewal fee it will be the case forever. Consequently, there is no 
point renewing the IPR because it will always cost more than it generates. The optimal stopping rule solving program (1) is then to renew the PBR as long as the rent exceeds the renewal fee and to withdraw the PBR as soon as the rent is below the renewal fee. This simple renewal rule due to Schankerman and Pakes (1986) is synthesized by the following proposition.

Proposition 1 If the renewal fee increases with the age of the PBR whereas the rent decreases due to depreciation, then $\tau_{i}^{*}=\operatorname{Inf}\left\{t \in\{0, \ldots, T\} ; R_{i, t}<C_{i, t}\right\}$ is the optimal stopping time that solves the value maximization program (1).

An important consequence of Proposition 1 is that the optimal decision to renew or to withdraw a PBR relies on the current values of the rent and of the renewal fee, but does not involve any expectation of future flows of profits, future flows of costs, future interest rates and future grants or withdrawals of PBRs on the same crop. It also explains why the approach proposed by Schankerman and Pakes (1986) has received much more attention in applied econometric works than the more general real option approach examined by Pakes (1986) or Baudry and Dumont (2006). In most of these applied econometric contributions, unobserved heterogeneity between IPRs is generally limited to unobserved heterogeneity in the initial rent at the date of application, or the date of grant. This is consistent with their goal to measure the pace of innovation at a sectoral, or even a macroeconomic, level. Nevertheless, we need to go one step further in order to identify which key variables may affect the rent and to assess the impact of exemption rules that are applied to PBRs and make them different from patents.

\subsection{Model specification}

Figure 1 highlights how heterogeneity in the initial rent and heterogeneity in the depreciation rate affect the optimal decision, described in Proposition 1, to renew or withdraw a PBR. Three PBRs with different time paths of the rent are considered. All of them face the same schedule of renewal fees that increase as the PBR ages. The two first PBRs (with respectively the time paths corresponding to $R_{1}$ and 
$R_{2}$ ) have a different initial rent due to vertical and/or horizontal differentiation between the two protected varieties but they face the same changes in economic conditions and thus have the same depreciation rate of the rent. As shown by Figure 1. the difference in the initial rent is a sufficient condition to generate a difference in lapse dates. As already stressed, the empirical literature on renewal decisions for IPRs (mainly for patents) focuses on this source of heterogeneity. In their seminal work, Schankerman and Pakes (1986) assume that heterogeneity in the initial rent is unexplained and show how to derive the probability distribution of lapse dates for a given cohort of patents from the probability distribution of the initial rent. Their model captures the influence of cohort specific variables but not the influence of patent specific variables. Srinivasan $(2003,2012)$ applies their approach to the case of PBRs. This approach is not suitable if one wants, for instance, to assess by how much the rent that accrues from a PBR protecting a given variety is sensitive to the size of the portfolio of PBRs protecting other varieties of the same crop and held by the same owner. Yet, the size of this portfolio is likely to be a key determinant of the market power of the PBRs holder and, consequently, a key determinant of the level of rent that can be extracted from a specific PBR. Following what Barney (2002) and Bessen (2008) suggest for patents, we assume that the initial rent has two components. The first one is a function of observed cohort specific variables or PBR specific variables that affect the initial level of the rent. The second component is unobserved heterogeneity captured by a random term that takes positive values. It is more convenient to assume that both of these two components, as well as the different observed variables of the first component, act multiplicatively. Indeed, the resulting specification of the initial rent guarantees that it always takes positive values. Accordingly, the initial rent $R_{i, 0}$ for a PBR $i$ may be written as

$$
R_{i, 0}=\alpha_{0}\left(\prod_{k=1}^{K} x_{i, k}^{\alpha_{k}}\right) \epsilon_{i}
$$

where $\alpha_{k}(k \in\{0, \ldots, K\})$ are parameters and the $x_{i, k}(k \in\{1, \ldots, K\})$ are variables that can be specific to the PBR and that influence the initial level of the rent. $\epsilon_{i}$ is 
an i.i.d. random term that captures unobserved heterogeneity.

Figure 1 - Renewal fees and annual rents

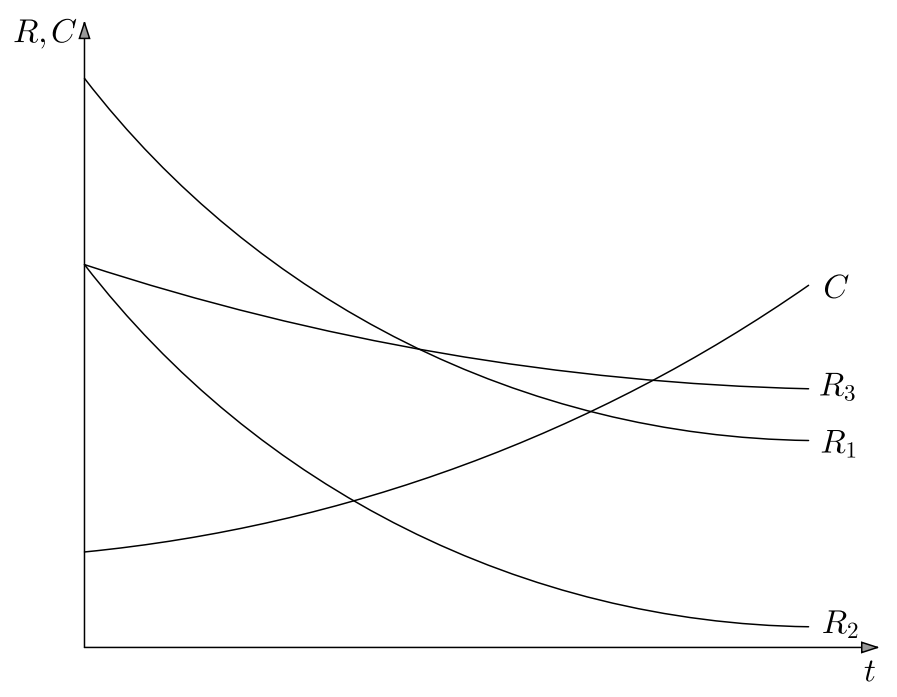

Differences in lapse dates of IPRs that result from heterogeneity in the rate of depreciation of the rent have been largely disregarded in the literature. Yet, as emphasized by Figure 1, different rates of depreciation lead to different withdrawal dates. In Figure 1, the PBR with the time path of the rent denoted $R_{3}$ has the same initial rent than the PBR with the time path $R_{2}$ but benefits from a lower depreciation rate. As a result, it is renewed for a longer period. Again, a difference in the depreciation rates can be induced by the dynamics of portfolios of PBRs owned by two PBR holders. The firm that holds the PBR with $R_{3}$ may have, for instance, been granted new PBRs on the same crop and, as a result, may have gained market power whereas the firm that holds the PBR with $R_{2}$ has not been granted new PBRs on this crop. As a result, the firm with $R_{3}$ has gained market power and is able to limit the erosion of the rent due to the arrival of new varieties whereas the firm with $R_{2}$ is passive, and thus incurs a loss of market power which induces a higher depreciation rate of the rent. In order to make this idea consistent with Proposition 1. we build on the model developed by Baudry and Dumont (2012) and postulate a logistic specification for the rate of depreciation $\delta_{i, s}$ of PBR $i$ at age $s$ : 


$$
\delta_{i, s}=\frac{1}{1+\exp \left(\beta * Z_{i, s}\right)},
$$

where $Z_{i, s}$ is a vector of variables that explain the dynamics of the depreciation rate. $\beta$ is the associated vector of parameters. It follows on that the rent $R_{i, t}$ of $\mathrm{PBR} i$ at age $t$ is specified as

$$
R_{i, t}=R_{i, 0} \prod_{s=1}^{t}\left(1-\delta_{i, s}\right)
$$

where $R_{i, 0}$ and $\delta_{i, s}$ are respectively given by (3) and (4). According to (4) and (5), a positive coefficient $\beta$ means that an increase in the associated variable $z$ induces a slowdown of the depreciation of the rent and thus favors the renewal of the PBR.

\subsection{The econometric model}

Combining equations (5) and Proposition 1, the optimal rule for a breeder to let his

PBR lapse becomes $R_{i, 0} \prod_{s=1}^{t}\left(1-\delta_{i, s}\right)<C_{i, t}$ and can be rearranged in the following log-linearized form

$$
\ln \epsilon_{i}<\ln C_{i, t}-\ln \alpha_{0}-\alpha_{k} * \sum_{k=1}^{K} \ln x_{i, k}-\sum_{s=1}^{t} \ln \left(1-\frac{1}{1+\exp \left(\beta * Z_{i, s}\right)}\right),
$$

The right hand side of this inequality provides a series of threshold values of the random term $\epsilon_{i}$, which increase with the age $t$, and are denoted $\Omega_{i, t}$. Below $\Omega_{i, t}$, abandonment of the PBR $i$ at age $t$ is optimal. Inequality (6) poses the basis for the econometric model.

The presence of the dynamic variables, altering the pace of the depreciation rate, calls for a peculiar strategy to estimate the model. If the depreciation rate was constant, the different thresholds $\Omega_{i, t}$ would remain unchanged as the PBR ages. If, moreover, the random terms $\epsilon_{i}$ are assumed to be log-normally distributed, then the corresponding econometric model would be an ordered Probit model like in Bessen 
(2008). Said in another way, the forecasted age of withdrawal would not be affected by the passage of time. But, as the expression of $\Omega_{i, t}$ actually involves dynamic variables, the relevant econometric model associated with the set of inequalities (6) has to account for the arrival of information. Therefore, we are interested in computing the optimal probability, $P r_{i, t}$, to withdraw PBR $i$ at age $t$, conditional on the fact that it has been kept in force until age $t-1$. A PBR $i$ is optimally abandoned at age $t$ only if $\ln \epsilon_{i}<\Omega_{i, t}$ and if it has survived until the previous period, $t-1$, which means that $\ln \epsilon_{i} \geq \Omega_{i, t-1}$. Consequently, the probability $\operatorname{Pr}_{i, t}$ is defined by the difference between the cumulative distribution function of $\epsilon_{i}$ evaluated at the two thresholds, divided by the cumulative distribution of the survival function at $t-1$

$$
\operatorname{Pr}_{i, t}=\frac{\Phi\left(\Omega_{i, t}\right)-\Phi\left(\Omega_{i, t-1}\right)}{1-\Phi\left(\Omega_{i, t-1}\right)}
$$

where $\Phi$ represents the cumulative distribution function of $\epsilon_{i}$ whereas $\left(1-\Phi\left(\Omega_{i, t-1}\right)\right)$ is the probability to keep the PBR in force until age $t-1$ and corresponds to the survival function. Notice that $\operatorname{Pr}_{i, t}$ is similar to the hazard rate in the literature of duration models. According to (5) and (3), in order to make sure that the rent always takes positive values, we assume that the random term $\epsilon_{i}$ is also positive. Therefore, we postulate that the random term $\epsilon_{i}$ is drawn from a log normal distribution ${ }^{3}$ Given that it has not yet lapsed, the log-likelihood of renewal versus withdrawal of PBR $i$ at age $t$ is defined as

$$
L_{i, t}=v_{i, t} * \ln P r_{i, t}+\left(1-v_{i, t}\right) \ln \left(1-P r_{i, t}\right),
$$

where $v_{i, t}$ equals 1 if $i$ is kept in force at age $t$ and $v_{i, t}$ equals 0 if $i$ is withdrawn at age $t$. The total log-likelihood for a sample of $N$ PBRs is obtained by summing the different $L_{i, t}$ over the period of life of each PBR $i$ and summing over the different

\footnotetext{
${ }^{3}$ In the literature, a discussion between different probability distributions exists. Indeed, it will have an impact on the right tail of the distribution of the value. We have tested other distributions, such as the Weibull and the Pareto distributions, but they did not fit the data as well as the lognormal distribution.
} 
PBRs $i$ :

$$
L_{t o t}=\sum_{i=1}^{N} \sum_{t=1}^{T_{i}} L_{i, t} .
$$

where $T_{i}$ is the observed age of withdrawal for PBR $i$. The parameters estimates are obtained as the outcome of the maximization of the total log-likelihood (9).

As already outlined when commenting equation (1), the likelihood of renewal versus withdrawal is conditional to the portfolio $P_{f}$ so that renewal decisions of the different PBRs within a same portfolio are interdependent. The conditionality to the portfolio $P_{f}$ of PBRs on varieties of the same crop hold by the same firm is captured by the presence of portfolio characteristics in regressors $x$ and/or $z$. Due to the interdependence between renewal decisions of PBRs within a same portfolio, there is a risk of endogeneity of these characteristics. This risk is dealt with an instrumental variable approach where endogenous control variables are replaced by their lagged values. More precisely, we define a one-year window centered on the date of grant of each PBR and we consider that all decisions relative to PBRs on the same crop that are taken within this window are simultaneous to the renewal decision for the PBR in interest. The values of the associated variables are thus replaced by their value on the previous one-year window.

\section{$3 \quad$ Data and results}

This section first presents the data used to estimate the model presented above. Estimation results are then broadly discussed. Last but not least, we present a test that provides some insights into the potential impact of the two exemption rules. It is argued that the impact of farmers' exemption on the renewal decision and, as a consequence, on the value of a PBR on a variety of a specific crop, can be assessed through the impact ceteris paribus of the total acreage devoted to that crop. The test of the impact of inventors' exemption is more subtle. It is based on a joint test of the impact of a grant of a new PBR and the withdrawal of a granted PBR on the 
same crop.

\subsection{Data}

The dataset on PBRs originates from the UPOV website. For each PBR granted in France, it provides information on the grant date, the withdrawal date, the nationality of the holder, the variety protected and, in the case of wheat, whether it is a winter or a spring variety. It covers the period from 1973 to 2011 for France. We extracted data for six species: the two main cultivated grain crops in France, wheat and maize; two oilseeds, sunflower and rapeseed; one protein crop, peas; and one tuberous crop, potatoes. These crops have been chosen for two reasons. First, because of their economic importance in the French agricultural sector. Second, because a sufficiently high number of PBRs has been granted in France over the period studied. Other crops, like sugar beet, may have a high economic importance for the French agricultural sector but the number of PBRs granted is too small for econometric purposes. Data on the price of crops come from FAO whereas data on compensatory payment per acre introduced by the Common Agricultural Policy (CAP) have been collected from different official sources related to the CAP. Figure 2 gives a snapshot of the dynamics of PBRs in force and of the dynamics of income per unit of harvested crop. 
Figure 2 - PBRs in Force and Farmers' Gross Income

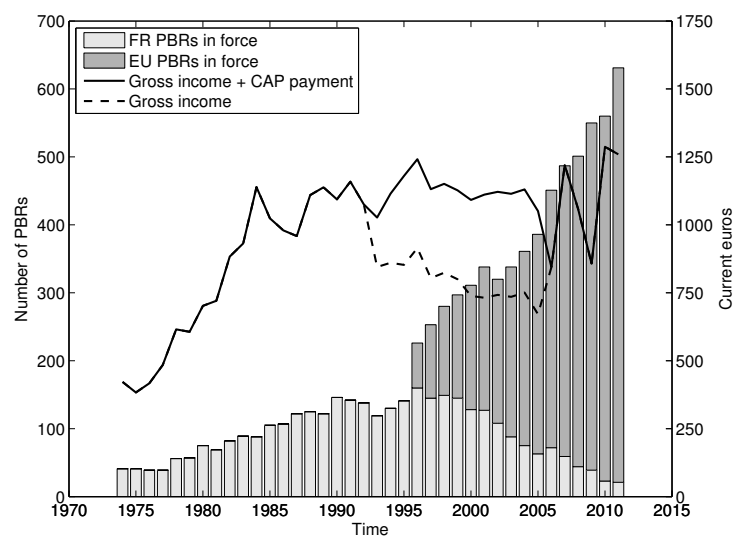

(a) Wheat

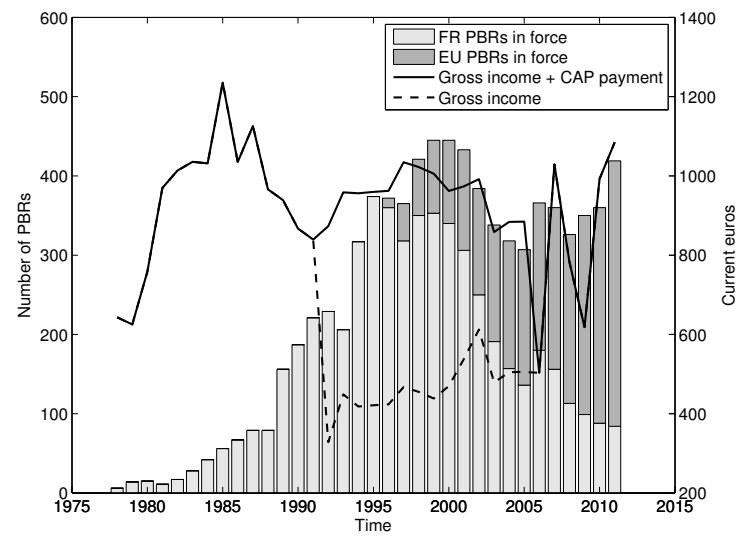

(c) Sunflower

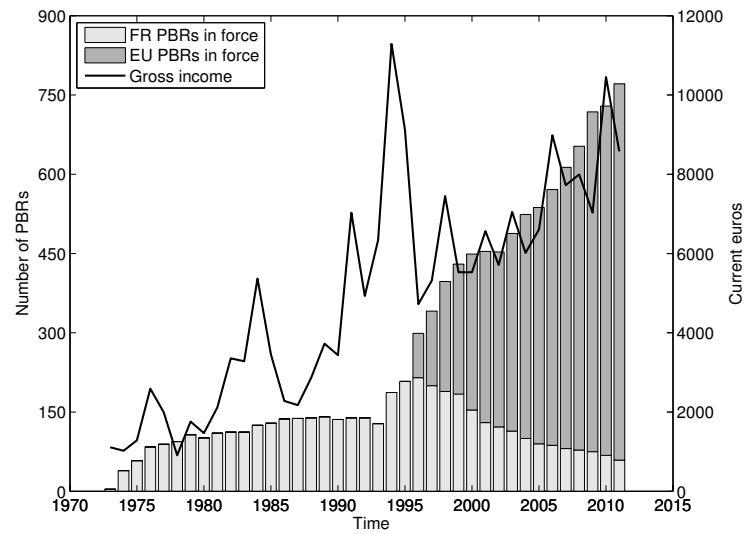

(e) Potatoes

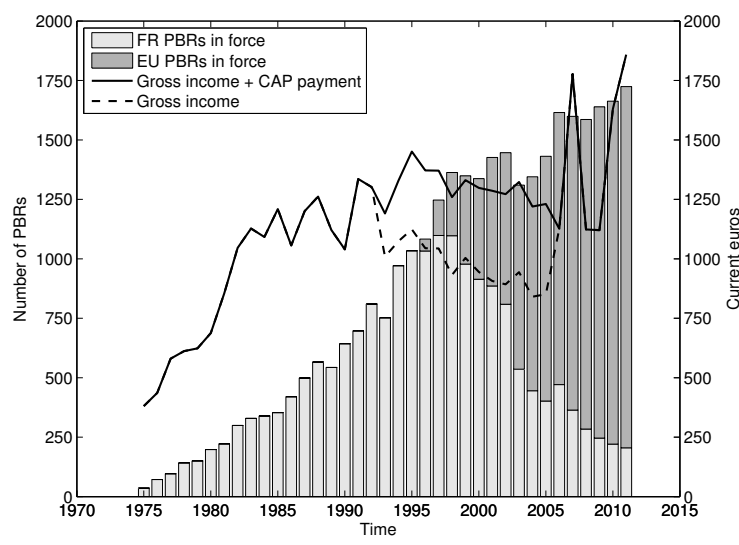

(b) Maize

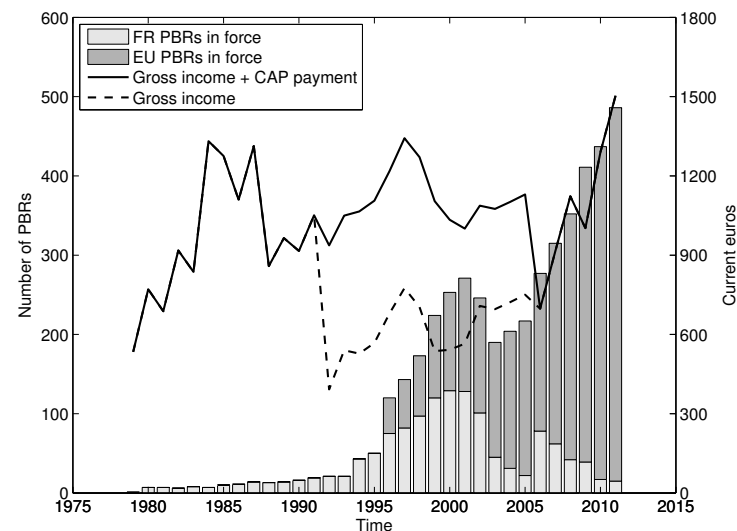

(d) Rapeseed

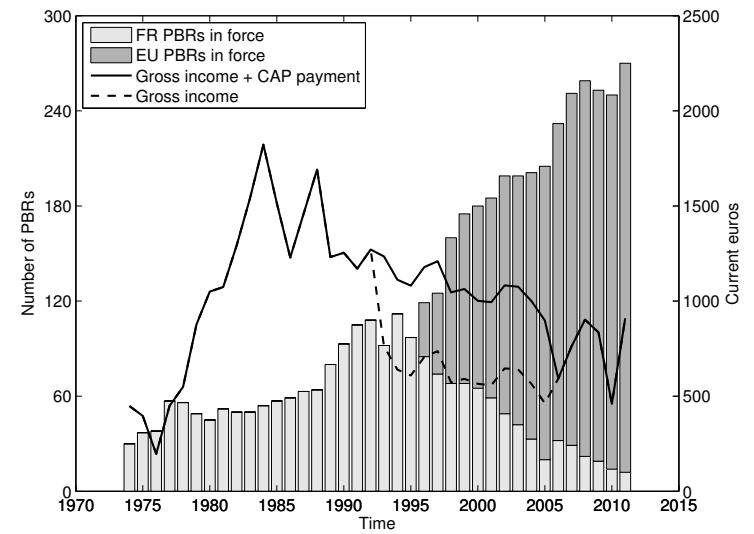

(f) Peas 
Regarding the count of PBRs, two major points call for comments. First, although our study focuses on renewal decisions for PBRs applied through the national channel, Figure 2 also reports the counts of PBRs applied through the European channel. Throughout our empirical analysis, these two types of PBRs are put together when it comes to capture the dynamics of PBRs. Indeed, Figure 2 highlights that the set up of the European channel in the mid 1990s induced a progressive substitution of European PBRs to national PBRs. At the end of the period studied, most PBRs were applied through the European channel which de facto induces a protection of the variety in France..$^{4}$ Second, what is displayed in Figure 2 is not counts of applied or granted PBRs but counts of PBRs that are in force at the different dates. Said another way, Figure 2 does not only account for grants but also for lapses.

Regarding the dynamics of gross income per hectare of land used to grow the different crops, Figure 2 distinguishes between the income with and the income without CAP compensatory payments received per unit of land to offset the effects of the reduction of guaranteed minimum prices. Indeed, in the mid 1990s, a reform of the CAP has lowered guaranteed minimum prices of the main crops and has set up payments decoupled from the actual production and linked to the surface grown. In spite of its aim to disconnect the support to farmers' income on the one hand and the level of production on the other hand, the CAP reform introduced payments differentiated by types of crops. In turn, this support has been reformed in the mid 2000s. Figure 2 clearly highlights that disregarding these compensatory payments biases, over a significant period, the measure of the profitability of the different crops. Figure 2 does not report the gross income without the compensatory payment in the case of potatoes because this payment was restricted to specific types of potatoes and we were not able to identify these types in our dataset.

\footnotetext{
${ }^{4}$ Contrary to patents applied to the European Patent Office, which are in force only in countries specifically targeted by the patent, PBRs applied through the European channel are "community" PBRs in the sense that they are systematically valid in all member states.
} 


\subsubsection{Control variables for the initial rent}

The variables used to explain heterogeneity in the initial value of the rent are either time invariant characteristics of PBRs or variables which value at the date of grant is a key determinant of the initial rent while their variation will affect the dynamics of the rent. Continuous variables affect the initial rent as specified in equation (3) and thus appear in a log-linear way in the threshold expression (6). Discrete variables appears in the form $\exp \left(\alpha_{k} x_{i, k}\right)$ in equation (3) and thus in a linear form in the threshold expression (6). Descriptive statistics of these variables are reported in Table 1. The list of these variables is the following:

- Hybrid is a dummy variable that takes the value one over the period where hybrid varieties are available and the value zero otherwise. This variable is used for rapeseed only $5^{5}$ Indeed, the emergence of hybrid varieties has been anterior to the grant of the first PBR for other crops where hybrid varieties exist so that it would have taken the value one over all the period studied.

- Init. price is the initial price of the crop at the date of grant. Ceteris paribus, the higher the price of a crop is, the higher is the demand for seeds of this crop. Consequently, the initial price of the crop is expected to have a positive impact on the initial rent. Wheat maize and potatoes varieties have a quite similar mean price (respectively $13.95 € / \mathrm{q} 14.09 € / \mathrm{q}$ and $15.08 € / \mathrm{q}$ ). Sunflower varieties have the highest mean of the initial price $(27.06 € / q)$, just before rapeseed varieties and varieties of peas (respectively $22.20 € / \mathrm{q}$ and $20.96 € / \mathrm{q}$ ). Price volatility is high for sunflower, potatoes, and to a lesser extent for peas, compared to other crops.

- Init. Area is the total acreage of land allocated to the crop. It measures the market size for PBRs of varieties of this crop. As such, it is expected to positively impact the initial rent for any PBR protecting a new variety of the crop. As will be detailed latter in this section, it is a key variable to test the impact of farmers' exemption. Because of the high magnitude of the variable, it has been normalized by its mean value over the whole period studied.

\footnotetext{
${ }^{5}$ The first hybrid variety of rapeseed in France, called Synergy and developed by INRA and Seracem, dates back to 1994 .
} 
- CAP 1992 captures the impact of the reform of the CAP implemented in 1992. The 1992 reform of the CAP has introduced public support to farmers, based on the surface of land grown in the main crops. The exact amount of payment received was differentiated by crops and by geographical areas. More precisely, a payment by ton of harvested crop was first defined. It was then multiplied by a reference yield varying on a geographical basis to convert it in a local payment per unit of surface. Because our study is national wide, historical data on yields at the national level have been used to obtain an average payment per hectare of land dedicated to each type of crop. This payment is used as a distinct control variable in order to capture the fact that the resulting income was conditional on the crop being grown but was decoupled from the productivity of the variety. Ceteris paribus, and more specifically for an unchanged price of the crop, CAP 1992 is thus expe! cted to give incentives to grow low cost varieties rather than new, innovative but more expensive, varieties.

- CAP 2006 measures a similar effect for the new reform of the CAP implemented in 2006. This new reform was intended to gradually suppress the system of decoupled payments introduced by the 1992 reform.

- EU PBR is a dummy variable that takes the value one for PBRs that were already protected by a European PBR at the date of grant of the national PBR.

- PBRs Applicant is the count of PBRs on the same crop in the portfolio of the PBR holder at the date of grant of that PBR, whatever the channel used to apply for these PBRs (national or European). Like in Figure 2, the count is limited to PBRs that are in force a the date considered. This variable may capture two opposite effects, so that its net impact on the initial value of the rent is uncertain. On the one hand, if the portfolio already contains numerous PBRs on the same crop, the grant of a new right is more likely to signal a minor improvement than if the portfolio contains less PBRs. Then, the initial rent for an additional PBR is expected to be lower, and the size of the portfolio at the date of grant will have a negative impact on the initial rent. On the other hand, a larger portfolio of PBRs at the date of grant may reveal ceteris paribus (and more specifically for a given 
number of PBRs, on the same crop, held by competitors) a higher market power on the market of seeds for that crop. Then, it is expected that the size of the portfolio of PBRs on the same crop at the date of grant has a positive impact on the initial rent. The average size of PBRs portfolio is higher for Maize (40 in average at the grant date) than for other crops, but it is probably due to the population size. In view of the population size, the mean is very high for rapeseed (25). The standard deviation is very close to the mean for all crops, which means that some applicants have very few rights in their portfolio whereas other may have more than hundreds.

- PBRs Competitors is similar to PBRs Applicant but for competitors. The two effects mentioned for PBRs Applicant occur but they both act negatively on the initial rent. Indeed, the larger the portfolio of PBRs on the same crop held by competitors, the more difficult it is to propose an original and innovative new variety. At the same time, it is more difficult to exercise a significant market power.

- French is a dummy variable that takes the value 1 if the PBRs' holder is French. Indeed, a national bias may appear. It is generally alleged that a national applicant has greater incentives to keep a right in force, because the domestic market is a major market for her and/or she has a better knowledge of the domestic agricultural sector. Approximatively half of the rights are concerned, except for wheat where it is up to three quarters and only a quarter for rapeseed.

- Spring is a dummy variable, available only for wheat, that takes the value 1 if the right protects a spring wheat variety. Only $8 \%$ of PBRs on wheat are concerned. The underlying idea is that the market of the spring wheat is a separate market.

\subsubsection{Control variables for the depreciation of the rent}

The variables that are assumed to affect the initial rent but are not time invariant are all assumed to have their variation or their variation rate affecting the depreciation rate of the rent. The corresponding variables are the following:

- Price change is the rate of variation of the price of the crop. An increase of the price of the crop may foster the demand for seeds of newly protected varieties at the detriment of older protected varieties. Indeed, the increase of the price of crops 
can encourage farmers to renew their seeds rather than use farm-saved seeds and/or can incentivize them to switch to the newest varieties. Both effects will increase the depreciation rate.

- Area change is the rate of variation of the total acreage of the crop. Like Price change, an increase of this variable can impact the dynamics of the rent in a positive or a negative direction. Intuitively, it is expected that an increase in acreage implies an increase of the market size for seeds and, consequently, it is intuitively expected that an increase in acreage induces a slow down of the depreciation. Nevertheless, an increase in the acreage of a crop may also result from the diffusion of new very competitive varieties that favors the conversion of land that was initially devoted to other crops. In such a case, it logically fosters the depreciation of the rent of previously granted PBRs.

- CAP 1992 change is the variations of gross income per hectare induced by the compensatory decoupled payment introduced by the CAP reform in 1992 and then gradually suppressed by the 2006 new reform.

- CAP 2006 change is a dummy variable that takes the value one for the year 2006 to take into account the revision of the CAP reform.

- $v E U P B R$ is a dummy variable that takes the value one for the year where the PBR is protected through the European PBR system. An increase of the depreciation rate is expected, caused by the overlap of the French PBR and the European PBR.

- New Rights App. is the flow of new PBRs obtained at the national or European level by the holder of the PBR in interest. Like the impact of PBRs Applicant on the initial rent, and for the same reasons, its effect on the depreciation rate can be ambivalent. On the one hand, an increase of the size of the portfolio of PBRs on the same crop held by the same owner can reduce the market opportunities for the PBR in interest and, consequently, can accelerate its depreciation. On the other hand, it can also strengthen the market power of the PBR owner and can thus slow down the depreciation of the rent.

- Exit Applicant is the opposite of New Rights App., it is the flow of PBRs 
withdrawn during the life of the PBRs in interest. Again, the withdrawal of PBRs on the same crop can release some room for the remaining PBR and slow down the depreciation of the rent. At the same time, it can also weaken the market power of the PBR holder and can thus accelerate the depreciation of the rent.

- New Rights Comp. is the flow of new national or European PBRs granted to other applicants during the life of the PBR in interest. It is clearly expected to increase the depreciation of the rent because of an increased competition due to newly PBRs granted to competitors.

- Exit Competitors is the opposite of New Rights Comp., it is the flow of PBRs held by other applicants and withdrawn during the life of the PBR in interest. It is thus expected to have a symmetric effect and to slow down the depreciation of the rent.

The last two variables play a key role to test the impact of inventors' exemption. This point will be made more explicit later in the article. For all these variables introduced as components of the vector $Z_{i, s}$ in the expression (4) of the depreciation rate, a positive (respectively negative) coefficient means that an increase of the variable weakens (respectively strengthens) the depreciation of the rent. In addition to these variables, a trend is introduced. It aims at capturing the fact that the depreciation rate may vary ceteris paribus as the PBR ages. 
Table 1 - Summary Statistics

\begin{tabular}{|c|c|c|c|c|c|c|}
\hline Variables & Wheat & Maize & Sunflower & Rapeseed & Potatoes & Peas \\
\hline $\begin{array}{l}\text { Hybrid } \\
\text { frequency }\end{array}$ & . & . & & 0.88 & . & \\
\hline Init. Price (€/quintal) & & & & & & \\
\hline mean & 13.95 & 14.09 & 27.06 & 22.20 & 15.08 & 20.96 \\
\hline std & 2.95 & 2.67 & 10.77 & 4.93 & 10.12 & 7.84 \\
\hline $\begin{array}{l}\text { Init. Area } \\
\text { mean }\end{array}$ & 1 & 1 & 1 & 1 & 1 & 1 \\
\hline std & 0.07 & 0.08 & 0.23 & 0.28 & 0.27 & 0.78 \\
\hline $\begin{array}{l}\text { CAP } 1992(€ / \text { hectare }) \\
\text { mean }\end{array}$ & 317.90 & 318.44 & 537.69 & 529.68 & . & 466.50 \\
\hline $\begin{array}{l}\text { std } \\
\text { CAP } 2006\end{array}$ & 43.03 & 39.32 & 32.52 & 45.09 & . & 13.52 \\
\hline $\begin{array}{l}\text { frequency } \\
\text { EU PBR }\end{array}$ & 0.05 & 0.07 & 0.08 & 0.11 & . & 0.06 \\
\hline $\begin{array}{l}\text { frequency } \\
\text { PBRs Applicant }\end{array}$ & 0.01 & 0.005 & 0.001 & 0.09 & 0.01 & 0.02 \\
\hline mean & 6.41 & 40.43 & 13.54 & 24.58 & 6.78 & 5.12 \\
\hline std & 5.77 & 41.68 & 13.61 & 26.79 & 7.05 & 3.66 \\
\hline $\begin{array}{l}\text { PBRs Competitors } \\
\text { mean }\end{array}$ & 132.14 & 752.2 & 241.26 & 111.13 & 114.54 & 77.94 \\
\hline $\begin{array}{l}\text { std } \\
\text { French }\end{array}$ & 99.31 & 417.6 & 129.00 & 80.08 & 79.44 & 51.30 \\
\hline $\begin{array}{l}\text { frequency } \\
\text { Spring }\end{array}$ & 0.75 & 0.56 & 0.59 & 0.41 & 0.26 & 0.52 \\
\hline $\begin{array}{l}\text { frequency } \\
\text { Price change }\end{array}$ & 0.08 & . & . & . & . & \\
\hline mean & 0.05 & 0.06 & 0.10 & 0.11 & 0.11 & 0.04 \\
\hline std & 0.04 & 0.04 & 0.06 & 0.05 & 0.13 & 0.02 \\
\hline $\begin{array}{l}\text { Area change } \\
\text { mean }\end{array}$ & 0.007 & -0.002 & 0.01 & 0.05 & -0.01 & 0.15 \\
\hline std & 0.01 & 0.02 & 0.04 & 0.04 & 0.02 & 0.44 \\
\hline $\begin{array}{l}\text { CAP } 1992 \text { change } \\
\text { mean }\end{array}$ & -1.75 & -5.30 & -13.07 & -16.91 & $\cdot$ & -0.66 \\
\hline $\begin{array}{l}\text { std } \\
\text { CAP } 2006 \text { change }\end{array}$ & 23.04 & 27.34 & 41.73 & 46.14 & . & 29.52 \\
\hline $\begin{array}{l}\text { frequency* } \\
\text { vEU PBR }\end{array}$ & 0.80 & 0.91 & 0.98 & 0.97 & . & 0.71 \\
\hline frequency* & 0.09 & 0.07 & 0.06 & 0.11 & 0.16 & 0.08 \\
\hline $\begin{array}{l}\text { New Rights App. } \\
\text { mean }\end{array}$ & 0.98 & 10.19 & 2.05 & 4.94 & 1.06 & 0.59 \\
\hline std & 0.19 & 2.92 & 1.34 & 2.15 & 0.31 & 0.24 \\
\hline $\begin{array}{l}\text { Exit Applicant } \\
\text { mean } \\
\text { std }\end{array}$ & $\begin{array}{l}0.87 \\
0.64\end{array}$ & $\begin{array}{l}7.41 \\
3.90\end{array}$ & $\begin{array}{l}1.87 \\
1.47\end{array}$ & $\begin{array}{l}3.49 \\
4.05\end{array}$ & $\begin{array}{l}0.67 \\
0.33\end{array}$ & $\begin{array}{l}0.68 \\
0.26\end{array}$ \\
\hline $\begin{array}{l}\text { New Rights Comp. } \\
\text { mean }\end{array}$ & 48.43 & 176.03 & 39.97 & 41.75 & 40.89 & 23.55 \\
\hline std & 8.38 & 25.13 & 9.29 & 5.87 & 3.77 & 2.36 \\
\hline $\begin{array}{l}\text { Exit Competitors } \\
\text { mean }\end{array}$ & 28.27 & 123.00 & 32.66 & 17.72 & 18.32 & 16.31 \\
\hline std & 4.46 & 18.19 & 5.68 & 5.38 & 3.49 & 2.13 \\
\hline Population size & 505 & 2879 & 829 & 247 & 382 & 323 \\
\hline Start date & 1974 & 1975 & 1978 & 1979 & 1973 & 1974 \\
\hline
\end{tabular}




\subsection{Results}

Tables 2 to 7 display the estimation results of the PBRs renewal model for each of the six crops studied. Six versions of the model have been considered. Model 1 is a basic model where neither the initial rent nor its depreciation rate are influenced by observed exogenous variables. Differences across PBRs in terms of renewal decisions thus only rely on unobserved heterogeneity in the initial rent. The initial values of parameters $\mu$ and $\sigma$ used for the numerical maximization of the log-likelihood are derived from the assumption that the depreciation rate amounts to $20 \%$ and that the value of the initial rent for each PBR is just consistent with the observed age of withdrawal. In other words, if a PBR $i$ has been withdrawn at age $\tau$ we assume that $R_{i, 0}=C_{i, \tau}(1-0.2)^{-\tau}$ where $C_{i, \tau}$ is the renewal fee at age $\tau$ for PBR $i$. The two parameters $\mu$ and $\sigma$ are then obtained as the mean and standard deviation of the distribution of the natural logarithm of $R_{i, 0}$ over the different PBRs. The estimated constant depreciation rate is reported in the row "Year 1". This depreciation rate substantially varies from one crop to another one. It ranges from $7.20 \%$ for potatoes to $17.97 \%$ for wheat. PBRs for Peas have a low depreciation rate $(10.12 \%)$ whereas PBRs for sunflower and rapeseed have a high depreciation rate (14.43\% and 16.29\%). PBRs for maize are characterized by a medium depreciation rate (12.38\%). For all crops, the estimated value of $\mu$ is close to 6 whereas more important differences are observed in terms of dispersion (parameter $\sigma$ ) which is relatively low for peas (at 0.8770) and high for wheat (at 1.2982). Applying formula (1), we have been able to simulate the value of each PBR in the dataset. The main features of the distribution of these values (mean value and quantiles) are reported in Table 8. PBRs on Potatoes and wheat have the highest mean and median value. PBRs on peas and rapeseed have the lowest mean and median values. For all crops, the distribution of PBRs' values is highly skewed, which is in line with results usually obtained for patents.

Model 2 may be thought of as the equivalent of the model developed by Schankerman and Pakes (1986) in the sense that the distribution of the initial rent can be 
affected by cohort specific variables but the depreciation rate is constant. The cohort-specific variables involved in Model 2 are the market price Init price of the crop at the date of application, the total acreage of the crop Init. Area at the date of application and the additional gross income per hectare of land resulting from the compensatory payments and captured by either CAP 1992 or CAP 2006. Estimates obtained for Model 1 are used as initial values of parameters common with Model 2 for the numerical maximization of the log-likelihood whereas the initial values of other coefficients are set at zero. Model 3 extends Model 2 with the inclusion of PBR-specific variables (PBRs Applicant, PBRs Competitors, EU PBR, French and, for wheat only, Spring) influencing the initial rent. Again, the initial values of parameters that are common with Model 2 are set to the estimated values obtained in Model 2 whereas the initial value of new coefficients are set to zero. Model 4 is a variant of Model 3 which allows for age-specific depreciation rate. More precisely, a trend is introduced in addition to the constant coefficient in the expression (4) of the depreciation rate. The last two rows of Tables 2 to 7 display the log-likelihood and the statistic LR used for the log-likelihood ratio test of restricting the model to the variant used to initialize the parameters. The log-likelihood ratio test almost always supports the extension made. The exceptions are Model 3 and Model 4 for wheat, Model 4 for rapeseed and Model 2 for potatoes. Models 2 and 3 lead to marginal changes in the distribution of PBR values compared to Model 1. Model 4 results in a more drastic change. It systematically results in an increase of all quantiles, which suggests that the whole distribution of PBRs values shifts to the right. Models 5 and 6 respectively extend Models 3 and 4 with the inclusion of variables that impact the depreciation of the rent (either cohort specific variables like Price change, Area Change, CAP 1992 change and CAP 2006 change or PBR specific variables like $v E U$ PBR, New Rights App, Exit Applicant, New Rights Comp. and Exit Competitors. Model 5 induces a shift of the distribution of PBRs values to the right, but the shift is smaller than the one induced by Model 4. Model 6 does not generate a systematic and significant additional shift of the distribution of PBRs values compared to Model 4. 
Cohort specific variables have a significant impact when taken all together (as shows the LR statistic for Model 2 versus Model 1), but their individual impact is generally not significant. The coefficient $\delta_{\text {trend }}$ is always positive and significant, except in Model 4 for rapeseed where it is still positive but not significant. Most of the time, it thus results in a slowdown of the depreciation rate as the PBR ages. Init. Price is found to have a low (albeit positive when it is significant) impact on initial rents. A more significant positive coefficient was expected. Price change, for its part, has a significant and negative impact on the depreciation rate of the rent for wheat and for rapeseed. For these crops, an increase of the market price induces a higher depreciation rate, probably because farmers are then keen to switch to more recent (and more expensive) varieties due to more favorable economic conditions. This reverses in favor to a significant positive effect for maize and sunflower whereas the effect is not significant for peas and potatoes. The impact of the additional gross income associated with CAP 1992 and CAP 2006 is seldom significant. Maize is the only crop having PBRs values affected by these variables. The associated negative coefficients indicate that compensatory payments have not offset the drop of the price of the harvested crop and, consequently, that the rent from selling protected seeds has fallen down. The arrival of hybrid varieties (dummy variable Hybrid) had no impact on the initial rents of PBRs for rapeseed. Comments on the impact of Init. Area are detailed in the next subsection because they play a key role to assess by how much the value of PBRs are affected by farmers' exemption. 
Table 2 - Results for wheat

\begin{tabular}{|c|c|c|c|c|c|c|}
\hline & Model 1 & Model 2 & Model 3 & Model 4 & Model 5 & Model 6 \\
\hline$\mu$ & $6.2605^{a}$ & $4.2150^{a}$ & $4.0583^{a}$ & 4.6796 & $4.4758^{a}$ & $5.5109^{b}$ \\
\hline$\sigma$ & $1.2982^{a}$ & $\begin{array}{l}3.0311 \\
1.2717^{a}\end{array}$ & $1.2752^{a}$ & $2.5633^{b}$ & $1.3519^{a}$ & $2.4059^{a}$ \\
\hline & 6.0468 & $\begin{array}{c}6.0589 \\
15166^{a}\end{array}$ & $\begin{array}{c}5.9919 \\
15087^{a}\end{array}$ & $\begin{aligned} 2.4506 \\
-02309\end{aligned}$ & $\begin{array}{l}5.6976 \\
1.3825^{a}\end{array}$ & \\
\hline$\delta_{\text {cons }}$ & $\begin{array}{l}1.5182^{a} \\
7.3713\end{array}$ & $\begin{array}{l}1.5166^{a} \\
7.3365\end{array}$ & $\begin{array}{l}1.5087^{a} \\
7.2244\end{array}$ & $\begin{array}{l}-0.2399 \\
-0.3252\end{array}$ & $\begin{array}{l}1.3825^{a} \\
5.5811\end{array}$ & \\
\hline$\delta_{\text {trend }}$ & & & & $0.0832^{a}$ & & $0.0764^{a}$ \\
\hline Depreciation rate & & & & & & \\
\hline Year 1 & 0.1797 & 0.1800 & 0.1811 & 0.5391 & 0.2000 & 0.4935 \\
\hline Year 10 & & & & 0.3562 & 0.1906 & 0.3303 \\
\hline Year 20 & & & & 0.1941 & 0.1693 & 0.1782 \\
\hline Init. Price & & $0.8007^{c}$ & 0.9323 & 1.9837 & 0.8907 & 1.4883 \\
\hline Init. Area & & $-2.2376^{c}$ & -2.2056 & -4.5941 & $-3.1237^{b}$ & $-5.2315^{c}$ \\
\hline CAP 1992 & & -0.0181 & -0.0127 & -0.0095 & -0.0326 & -0.0343 \\
\hline CAP 2006 & & $\begin{array}{l}-0.5708 \\
-0.3737\end{array}$ & $\begin{array}{l}-0.2894 \\
-0.3467\end{array}$ & $\begin{array}{l}-0.10 r 9 \\
-0.6610\end{array}$ & $\begin{array}{l}-0.6306 \\
-0.3913\end{array}$ & $\begin{array}{l}-0.3607 \\
-0.4452\end{array}$ \\
\hline & & -0.9943 & -0.8034 & -0.7294 & -0.7878 & -0.5142 \\
\hline EU PBR & & & $\begin{array}{l}0.2176 \\
0.3621\end{array}$ & $\begin{array}{l}0.4736 \\
0.4004\end{array}$ & $\begin{array}{c}0.0432 \\
0.0612\end{array}$ & $\begin{array}{l}-0.0504 \\
-0.0406\end{array}$ \\
\hline PBRs Applicant & & & $\begin{array}{l}-0.0810 \\
-1.2169\end{array}$ & $\begin{array}{l}-0.1547 \\
-1.0596\end{array}$ & $\begin{array}{l}0.0916 \\
1.1501\end{array}$ & $\begin{array}{l}0.2441^{c} \\
1.6750\end{array}$ \\
\hline PBRs Competitors & & & -0.0010 & -0.0306 & -0.0655 & -0.1246 \\
\hline French & & & -0.0967 & -0.1907 & -0.2214 & -0.3470 \\
\hline Spring & & & $\begin{array}{c}-0.0351 \\
0.0303 \\
0.1410\end{array}$ & $\begin{array}{c}-0.0231 \\
0.1003 \\
0.2317\end{array}$ & $\begin{array}{c}-1.5354 \\
0.0559 \\
0.2491\end{array}$ & $\begin{array}{c}0.1432 \\
0.3518\end{array}$ \\
\hline Price change & & & & & $-0.8877^{b}$ & $-0.8816^{b}$ \\
\hline Area change & & & & & -0.6528 & -0.7725 \\
\hline CAP 1992 change & & & & & -0.0003 & -0.0004 \\
\hline CAD 2006 hhon & & & & & $\begin{array}{l}-0.1575 \\
-0.0160\end{array}$ & $\begin{array}{l}-0.2146 \\
-0.1486\end{array}$ \\
\hline UAF ZU00 change & & & & & -0.0213 & -0.1991 \\
\hline vEU PBR & & & & & $\begin{array}{l}16.3214 \\
0.0000\end{array}$ & $\begin{array}{l}7.3265 \\
0.0076\end{array}$ \\
\hline New Rights App. & & & & & -0.0184 & -0.0181 \\
\hline Exit Applicant & & & & & $-0.1223^{a}$ & $-0.1491^{a}$ \\
\hline New Rights Comp. & & & & & 0.0046 & 0.0031 \\
\hline Exit Competitors & & & & & $\begin{array}{c}0.0019 \\
0.3822\end{array}$ & $\begin{array}{c}-0.0000 \\
-0.0012\end{array}$ \\
\hline $\log \mathrm{L}$ & -1421.5161 & -1412.9694 & -1411.8081 & -1404.2124 & -1371.7157 & -1363.7974 \\
\hline LR & 10.7207 & 17.0935 & 2.3225 & 15.1915 & 80.1848 & 80.8299 \\
\hline
\end{tabular}

Note a, b and c mean significant at $1 \%, 5 \%$ and $10 \%$ respectively 
Table 3 - Results for maize

\begin{tabular}{|c|c|c|c|c|c|c|}
\hline & Model 1 & Model 2 & Model 3 & Model 4 & Model 5 & Model 6 \\
\hline$\mu$ & $\begin{array}{l}5.6674^{a} \\
89.0793\end{array}$ & $\begin{array}{l}6.2684^{a} \\
19.2889\end{array}$ & $\begin{array}{l}5.7374^{a} \\
15.5032\end{array}$ & $7.8917^{a}$ & $\begin{array}{l}5.4478^{a} \\
12.6289\end{array}$ & $7.2642^{a}$ \\
\hline$\sigma$ & $1.0423^{a}$ & $1.0078^{a}$ & $0.9971^{a}$ & $1.9581^{a}$ & $1.0566^{a}$ & $2.1529^{a}$ \\
\hline & $\begin{array}{l}17.3108 \\
10570^{a}\end{array}$ & $\begin{array}{l}17.7761 \\
1.0271 a\end{array}$ & $\begin{array}{l}17.9604 \\
10221 a\end{array}$ & 7.4463 & $\begin{array}{l}17.0103 \\
0\end{array}$ & 21.0497 \\
\hline$\delta_{\text {cons }}$ & $\begin{array}{l}1.9572^{a} \\
26.7968\end{array}$ & $\begin{array}{l}1.9371^{a} \\
26.8717\end{array}$ & $\begin{array}{l}1.9331^{a} \\
26.9566\end{array}$ & $\begin{array}{c}0.0023 \\
0.0094\end{array}$ & $\begin{array}{l}2.0266^{a} \\
20.7367\end{array}$ & \\
\hline$\delta_{\text {trend }}$ & & & & $\begin{array}{l}0.1054^{a} \\
10.5286\end{array}$ & & $\begin{array}{l}0.1218^{a} \\
20.4178\end{array}$ \\
\hline Depreciation rate & & & & & & \\
\hline Year 1 & 0.1238 & 0.1260 & 0.1264 & 0.4731 & 0.1261 & 0.4999 \\
\hline Year 10 & & & & 0.2581 & 0.1359 & 0.2797 \\
\hline Year 20 & & & & 0.1082 & 0.1250 & 0.1009 \\
\hline Init. Price & & -0.0971 & 0.2427 & $\begin{array}{c}0.6013 \\
1.6396\end{array}$ & $\begin{array}{l}0.2656 \\
1.4414\end{array}$ & $\begin{array}{l}0.6191 \\
1.4686\end{array}$ \\
\hline Init. Area & & -0.3398 & 0.0297 & 0.2450 & -0.0378 & 0.1232 \\
\hline CAP 1992 & & $-0.1008^{a}$ & $-0.0544^{a}$ & $-0.0940^{a}$ & $-0.0493^{a}$ & $-0.0697^{c}$ \\
\hline CAP 2006 & & $\begin{array}{l}-9.7666 \\
-0.7354^{a}\end{array}$ & $\begin{array}{c}-3.4281 \\
-0.4666^{a}\end{array}$ & $\begin{array}{l}-2.7912 \\
-0.8477^{a}\end{array}$ & $\begin{array}{l}-2.7873 \\
-0.4164^{a}\end{array}$ & $\begin{array}{l}-1.8185 \\
-0.5716^{c}\end{array}$ \\
\hline & & -6.8960 & -3.3252 & -2.8569 & -2.7427 & -1.7620 \\
\hline EU PBR & & & $\begin{array}{l}0.3298 \\
1.1053\end{array}$ & $\begin{array}{c}0.5906 \\
1.0171\end{array}$ & $\begin{array}{l}0.3971 \\
1.1486\end{array}$ & $\begin{array}{l}1.0089 \\
1.4554\end{array}$ \\
\hline PBRs Applicant & & & $\begin{array}{l}-0.1102^{a} \\
-6.6866\end{array}$ & $\begin{array}{l}-0.2178^{a} \\
-5.1446\end{array}$ & $\begin{array}{l}-0.0865^{a} \\
-4.7784\end{array}$ & $\begin{array}{c}-0.1095^{a} \\
-2.8409\end{array}$ \\
\hline PBRs Competitors & & & -0.0431 & $\begin{array}{l}-0.0997 \\
-1.5961\end{array}$ & -0.0097 & $\begin{array}{l}-0.0024 \\
-0.0298\end{array}$ \\
\hline French & & & $\begin{array}{l}0.1728^{a} \\
3.9734\end{array}$ & $\begin{array}{l}0.3503^{a} \\
3.6125\end{array}$ & $\begin{array}{l}0.2051^{a} \\
4.1905\end{array}$ & $\begin{array}{l}0.3557^{a} \\
3.7183\end{array}$ \\
\hline Price change & & & & & $\begin{array}{l}0.7354^{a} \\
4.1159\end{array}$ & $0.3258^{c}$ \\
\hline Area change & & & & & -0.3012 & $-0.8153^{c}$ \\
\hline CAP 1992 change & & & & & -0.0003 & -0.0011 \\
\hline CAP 2006 change & & & & & -0.1150 & -0.5541 \\
\hline vEU PBR & & & & & $\begin{aligned} & -0.3065 \\
-1.1774^{a} & \end{aligned}$ & $\begin{array}{r}-1.6269 \\
-1.0863^{a}\end{array}$ \\
\hline & & & & & -6.1439 & -5.3799 \\
\hline New Rights App. & & & & & $\begin{array}{l}0.0162^{a} \\
10.5397\end{array}$ & $\begin{array}{l}0.0136^{a} \\
9.1173\end{array}$ \\
\hline Exit Applicant & & & & & $\begin{array}{l}-0.0233^{a} \\
-20.8613\end{array}$ & $\begin{array}{l}-0.0278^{a} \\
-19.7214\end{array}$ \\
\hline New Rights Comp. & & & & & $-0.0016^{a}$ & $-0.0015^{a}$ \\
\hline Exit Competitors & & & & & $0.0012^{a}$ & $0_{2.1911}^{0.0009^{b}}$ \\
\hline $\log \mathrm{L}$ & -7903.8144 & -7799.0995 & -7763.7856 & -7704.5771 & -7566.8681 & -7458.0741 \\
\hline LR & 158.4946 & 209.4297 & 70.6279 & 118.4170 & 393.8350 & 493.0058 \\
\hline
\end{tabular}


Table 4 - Results for sunflower

\begin{tabular}{|c|c|c|c|c|c|c|}
\hline & Model 1 & Model 2 & Model 3 & Model 4 & Model 5 & Model 6 \\
\hline$\mu$ & $\begin{array}{l}5.8960^{a} \\
38.3255\end{array}$ & $3.0159^{b}$ & $2.4829^{c}$ & 0.8168 & $3.4235^{b}$ & $\begin{array}{l}3.7910 \\
1.0765\end{array}$ \\
\hline$\sigma$ & $1.1317^{a}$ & $1.0765^{a}$ & $1.0016^{a}$ & $2.5433^{a}$ & $1.1514^{a}$ & $2.1978^{a}$ \\
\hline & 8.5852 & 8.7156 & $\begin{array}{l}9.2452 \\
1.8140^{a}\end{array}$ & 3.6764 & 8.0672 & 8.7991 \\
\hline$\partial_{\text {cons }}$ & $\begin{array}{l}1.7802^{a} \\
12.2027\end{array}$ & $\begin{array}{l}1.7788^{\circ} \\
12.2765\end{array}$ & $\begin{array}{l}1.8149^{a} \\
13.0584\end{array}$ & $\begin{array}{l}-0.6629 \\
-1.2966\end{array}$ & $\begin{array}{l}1.7854^{a} \\
7.7306\end{array}$ & \\
\hline$\delta_{\text {trend }}$ & & & & $0.1289^{a}$ & & $0.1017^{a}$ \\
\hline Depreciation rate & & & & & & \\
\hline Year 1 & 0.1443 & 0.1444 & 0.1400 & 0.6304 & 0.1640 & 0.5095 \\
\hline Year 10 & & & & 0.3484 & 0.1643 & 0.3011 \\
\hline Year 20 & & & & 0.1284 & 0.1314 & 0.1164 \\
\hline Init. Price & & $0.8933^{b}$ & $1.0320^{a}$ & $2.7273^{a}$ & $0.9778^{b}$ & $1.7665^{b}$ \\
\hline Init. Area & & 0.0905 & 0.1387 & 0.2956 & $0.5497^{b}$ & $1.0550^{b}$ \\
\hline CAP 1992 & & -0.0000 & 0.0582 & 0.1576 & 0.0506 & 0.0977 \\
\hline CAP 2006 & & -0.0795 & -0.0537 & -0.1538 & -0.2329 & -0.4496 \\
\hline DDP & & -0.2908 & -0.1973 & -0.2234 & -0.6965 & -0.6684 \\
\hline EU PBR & & & $\begin{array}{l}-1.5178 \\
-0.0111\end{array}$ & $\begin{array}{c}-4.0039 \\
-0.0120\end{array}$ & $\begin{array}{l}-1.0203 \\
-0.0037\end{array}$ & $\begin{array}{l}-1.8175 \\
-0.0032\end{array}$ \\
\hline PBRs Applicant & & & $\begin{array}{l}-0.2425^{a} \\
-5.5983\end{array}$ & $-0.6193^{a}$ & $-0.1769^{a}$ & $-0.2820^{a}$ \\
\hline PBRs Competitors & & & 0.0176 & 0.0741 & -0.0697 & -0.1184 \\
\hline French & & & $\begin{array}{c}0.3639^{a} \\
4.1187\end{array}$ & $0_{2.9878}^{0.9961^{a}}$ & $0.3348^{a}$ & $\begin{array}{c}0.7046^{a} \\
3.6008\end{array}$ \\
\hline Price change & & & & & $0.9397^{a}$ & $0.6214^{b}$ \\
\hline Area change & & & & & $\begin{array}{l}1.5608^{a} \\
29016\end{array}$ & 0.7256 \\
\hline CAP 1992 change & & & & & 0.0003 & 0.0002 \\
\hline CAP 2006 change & & & & & 0.2785 & 0.1977 \\
\hline vEU PBR & & & & & $-1.8480^{a}$ & $-2.0057^{a}$ \\
\hline New Rights App. & & & & & -0.0065 & -0.0035 \\
\hline Exit Applicant & & & & & $-0.0556^{a}$ & $-0.0665^{a}$ \\
\hline New Rights Comp. & & & & & $\begin{array}{c}-7.2902 \\
-0.0050^{a}\end{array}$ & $\begin{array}{l}-7.3240 \\
-0.0047^{a}\end{array}$ \\
\hline Exit Competitors & & & & & $\begin{array}{c}-2.9169 \\
0.0048^{c} \\
1.7603\end{array}$ & $\begin{array}{c}0.8099 \\
0.0039 \\
1.5147\end{array}$ \\
\hline $\log L$ & -2247.1674 & -2214.3653 & -2177.1045 & -2152.2078 & -2117.2337 & -2092.8894 \\
\hline LR & 34.9137 & 65.6043 & 74.5216 & 49.7933 & 119.7416 & 118.6368 \\
\hline
\end{tabular}

Note a, b and c mean significant at $1 \%, 5 \%$ and $10 \%$ respectively 
Table 5 - Results for rapeseed

\begin{tabular}{|c|c|c|c|c|c|c|}
\hline & Model 1 & Model 2 & Model 3 & Model 4 & Model 5 & Model 6 \\
\hline$\mu$ & $\begin{array}{l}5.8003^{a} \\
24.2496\end{array}$ & $\begin{array}{l}0.2562 \\
0.1273\end{array}$ & 0.8535 & 0.4933 & $\begin{array}{l}2.5624 \\
1.2917\end{array}$ & $\begin{array}{l}4.5017 \\
1.4129\end{array}$ \\
\hline$\sigma$ & $1.0635^{a}$ & $1.0362^{a}$ & $0.8777^{a}$ & $1.2056^{a}$ & $0.7904^{a}$ & $1.0520^{a}$ \\
\hline$\delta_{\text {cons }}$ & $1.6371^{a}$ & $1.4120^{a}$ & $1.5438^{a}$ & 0.6241 & $1.0285^{a}$ & 9.6794 \\
\hline$\delta_{\text {trend }}$ & & 5.7184 & 8.5973 & $\begin{array}{l}1.1257 \\
0.0544\end{array}$ & 4.0240 & $0.0767^{a}$ \\
\hline Depreciation rate & & & & 1. & & 36519 \\
\hline Year 1 & 0.1629 & 0.1959 & 0.1760 & 0.3366 & 0.1736 & 0.3178 \\
\hline Year 10 & & & & 0.2372 & 0.1595 & 0.2054 \\
\hline Year 20 & & & & 0.1529 & 0.0777 & 0.0608 \\
\hline Hybrid & & -2.1019 & -1.6899 & -2.2982 & -1.9459 & -2.5054 \\
\hline Init. Price & & $\begin{array}{l}-1.4696 \\
1.8812^{a}\end{array}$ & $\begin{array}{l}-0.9852 \\
2.6321^{a}\end{array}$ & $\begin{array}{l}-0.9364 \\
3.4407^{a}\end{array}$ & $\begin{array}{l}-1.6270 \\
2.0554^{a}\end{array}$ & $\begin{array}{l}-1.2371 \\
2.0577^{b}\end{array}$ \\
\hline Init. Area & & $\begin{array}{r}3.1129 \\
-0.6497^{c}\end{array}$ & $\begin{array}{l}6.5082 \\
2.5658^{a}\end{array}$ & $\begin{array}{l}6.1943 \\
3.4371^{a}\end{array}$ & $\begin{array}{l}4.0335 \\
1.2667^{b}\end{array}$ & $\begin{array}{l}2.2918 \\
1.0232\end{array}$ \\
\hline & & -1.6746 & 4.1922 & 3.3542 & 2.1398 & 1.2448 \\
\hline CAP 1992 & & $\begin{array}{l}0.3585 \\
1.5729\end{array}$ & $\begin{array}{l}0.4367^{c} \\
1.6911\end{array}$ & $\begin{array}{c}0.5886 \\
1.5892\end{array}$ & $\begin{array}{c}0.2787 \\
1.4874\end{array}$ & $\begin{array}{c}0.2801 \\
0.8597\end{array}$ \\
\hline CAP 2006 & & 1.4583 & 1.5857 & 2.1492 & 0.6907 & 0.5042 \\
\hline EU PBR & & & -0.6980 & -0.9643 & -0.5844 & -0.8271 \\
\hline PBRs Applicant & & & $-0.1136^{b}$ & $-0.1588^{b}$ & $\begin{array}{l}-0.9959 \\
-0.0453\end{array}$ & $\begin{array}{l}-1.0910 \\
-0.0352\end{array}$ \\
\hline PBRs Competitors & & & $\begin{array}{c}-2.2775 \\
-0.7582^{a}\end{array}$ & $\begin{array}{l}-2.1708 \\
-1.0305^{a}\end{array}$ & $\begin{array}{r}-0.7898 \\
-0.5496^{a}\end{array}$ & $\begin{array}{r}-0.4062 \\
-0.6499^{a}\end{array}$ \\
\hline & & & -4.6739 & -3.6036 & -3.5323 & -3.0255 \\
\hline French & & & $\begin{array}{l}-0.3297^{a} \\
-2.6135\end{array}$ & $\begin{array}{l}-0.4601^{b} \\
-2.2520\end{array}$ & $\begin{array}{l}-0.3498^{b} \\
-2.4942\end{array}$ & $\begin{array}{l}-0.4857^{a} \\
-2.6833\end{array}$ \\
\hline Price change & & & & & $-4.0620^{a}$ & $-4.2253^{a}$ \\
\hline Area change & & & & & 0.5957 & 0.4798 \\
\hline CAP 1992 change & & & & & $\begin{array}{l}-0.0023 \\
-1.2199\end{array}$ & $\begin{array}{l}-0.0021 \\
-12004\end{array}$ \\
\hline CAP 2006 change & & & & & 0.4451 & 0.6714 \\
\hline vEU PBR & & & & & $-1.6139^{a}$ & $-1.4198^{a}$ \\
\hline New Rights App. & & & & & $\begin{array}{c}-3.9581 \\
0.0350^{b}\end{array}$ & $\begin{array}{c}-3.3485 \\
0.0359^{b} \\
2.2122\end{array}$ \\
\hline Exit Applicant & & & & & $-0.0293^{a}$ & $-0.0330^{a}$ \\
\hline New Rights Comp. & & & & & $0.0327^{a}$ & $0.0303^{a}$ \\
\hline Exit Competitors & & & & & $\begin{array}{c}-0.0139^{a} \\
-2.9081\end{array}$ & $\begin{array}{l}-0.0122^{a} \\
-2.7406\end{array}$ \\
\hline $\log \mathrm{L}$ & -635.1797 & -601.1094 & -581.8236 & -581.0425 & -539.8310 & -537.8602 \\
\hline LR & 9.4522 & 68.1405 & 38.5716 & 1.5623 & 83.9853 & 86.3645 \\
\hline
\end{tabular}

Note a, b and c mean significant at $1 \%, 5 \%$ and $10 \%$ respectively 
Table 6 - Results for peas

\begin{tabular}{|c|c|c|c|c|c|c|}
\hline & Model 1 & Model 2 & Model 3 & Model 4 & Model 5 & Model 6 \\
\hline$\mu$ & $\begin{array}{l}5.4673^{a} \\
43.8767\end{array}$ & $\begin{array}{l}3.6982^{a} \\
3.3605\end{array}$ & $\begin{array}{l}3.8055^{a} \\
3.1778\end{array}$ & $4.2015^{b}$ & $4.2425^{a}$ & $5.8555^{c}$ \\
\hline$\sigma$ & $0.8770^{a}$ & $0.8382^{a}$ & $0.8106^{a}$ & $1.2308^{a}$ & $0.8832^{a}$ & $2.1052^{a}$ \\
\hline & & & & 3.8504 & 7.1775 & 7.0747 \\
\hline$\delta_{\text {cons }}$ & $\begin{array}{l}2.1839^{a} \\
14.2503\end{array}$ & $\begin{array}{l}2.1886^{a} \\
12.4593\end{array}$ & $\begin{array}{l}2.2138^{a} \\
12.6762\end{array}$ & $\begin{array}{l}0.7582 \\
1.3867\end{array}$ & ${ }_{9.5167}^{2.4267^{a}}$ & \\
\hline$\delta_{\text {trend }}$ & & & & $0.0875^{a}$ & & $0.1304^{a}$ \\
\hline Depreciation rate & & & & & & \\
\hline Year 1 & 0.1012 & 0.1008 & 0.0985 & 0.3003 & 0.1123 & 0.5318 \\
\hline Year 10 & & & & 0.1634 & 0.1081 & 0.2767 \\
\hline Year 20 & & & & 0.0753 & 0.1177 & 0.1111 \\
\hline Init. Price & & $0.5739^{c}$ & $0.5965^{c}$ & 0.8894 & 0.4421 & 0.8863 \\
\hline Init. Area & & -0.0382 & -0.0245 & -0.0327 & -0.0770 & -0.1604 \\
\hline CAP 1992 & & 0.0133 & 0.0118 & 0.0177 & 0.0072 & 0.0155 \\
\hline CAP 2006 & & -0.3409 & -0.4994 & -0.7812 & -0.6519 & -1.5312 \\
\hline EU PBR & & & $\begin{array}{l}-1.3212 \\
0.8509^{b}\end{array}$ & $\begin{array}{l}-1.3137 \\
1.3433^{b}\end{array}$ & $\begin{array}{l}-1.4985 \\
1.0385^{b}\end{array}$ & $\begin{array}{l}-1.3996 \\
2.7232^{a}\end{array}$ \\
\hline PBRs Applicant & & & $\begin{aligned} & 2.3319 \\
- & 0.1497^{b}\end{aligned}$ & $\begin{array}{r}2.1934 \\
-0.2228^{b}\end{array}$ & $\begin{array}{c}2.3881 \\
-0.1113\end{array}$ & $\begin{array}{c}2.5994 \\
-0.2059\end{array}$ \\
\hline PBRs Competitors & & & $\begin{array}{l}-2.2016 \\
-0.0047\end{array}$ & $\begin{array}{l}-2.0287 \\
-0.0183\end{array}$ & $\begin{array}{c}-1.3992 \\
0.0146\end{array}$ & $\begin{array}{c}-1.0386 \\
0.0694\end{array}$ \\
\hline & & & -0.0456 & -0.1123 & 0.1432 & 0.2745 \\
\hline French & & & $\begin{array}{c}0.0801 \\
0.8517\end{array}$ & $\begin{array}{c}0.1187 \\
0.8139\end{array}$ & $\begin{array}{c}0.1170 \\
1.0667\end{array}$ & $\begin{array}{l}0.2627 \\
0.9785\end{array}$ \\
\hline Price change & & & & & -0.1921 & -0.1980 \\
\hline Area change & & & & & $-0.3100^{a}$ & $-0.2321^{c}$ \\
\hline CAP 1992 change & & & & & -0.0014 & -0.0015 \\
\hline CAP 2006 change & & & & & $\begin{array}{l}-1.2622 \\
-0.1074\end{array}$ & $\begin{array}{l}-1.4811 \\
-0.1639\end{array}$ \\
\hline & & & & & -0.1324 & -0.2129 \\
\hline vEU PBR & & & & & $\begin{array}{l}-1.6526^{b} \\
-2.4317\end{array}$ & $\begin{array}{c}-1.3499^{c} \\
-1.7929\end{array}$ \\
\hline New Rights App. & & & & & $\begin{array}{l}0.1695^{a} \\
2.5909\end{array}$ & $\begin{array}{l}0.1502^{a} \\
2.5827\end{array}$ \\
\hline Exit Applicant & & & & & $-0.2143^{a}$ & $-0.2290^{a}$ \\
\hline New Rights Comp. & & & & & $-0.0107^{c}$ & $-0.0126^{b}$ \\
\hline Exit Competitors & & & & & $\begin{array}{c}0.0002 \\
0.0168\end{array}$ & $\begin{array}{c}0.0014 \\
0.1156\end{array}$ \\
\hline $\log \mathrm{L}$ & -886.5782 & -874.9334 & -868.0833 & -862.2925 & -850.1177 & -842.0035 \\
\hline LR & 27.6205 & 23.2897 & 13.7002 & 11.5815 & 35.9311 & 40.5780 \\
\hline
\end{tabular}

Note a, b and c mean significant at $1 \%, 5 \%$ and $10 \%$ respectively 
Table 7 - Results for potatoes

\begin{tabular}{|c|c|c|c|c|c|c|}
\hline & Model 1 & Model 2 & Model 3 & Model 4 & Model 5 & Model 6 \\
\hline$\mu$ & $\begin{array}{l}5.8998^{a} \\
28.9615\end{array}$ & $\begin{array}{l}6.0588^{a} \\
16.5530\end{array}$ & $\begin{array}{l}6.2858^{a} \\
12.4419\end{array}$ & $\begin{array}{l}8.2463^{a} \\
6.0382\end{array}$ & $\begin{array}{l}6.9552^{a} \\
10.2189\end{array}$ & ${ }_{9.1841}^{10.8305^{a}}$ \\
\hline$\sigma$ & $\begin{array}{l}28.9615 \\
1.0211^{a}\end{array}$ & $\begin{array}{l}10.5350 \\
1.0271^{a}\end{array}$ & $0.9905^{a}$ & $\begin{array}{l}0.0382 \\
1.6033^{a}\end{array}$ & $\begin{array}{l}10.2189 \\
1.2124^{a}\end{array}$ & $\begin{array}{l}9.1841 \\
2.4474^{a}\end{array}$ \\
\hline$\delta_{\text {conn }}$ & 2.0544 & 2.8688 & $\begin{array}{l}5.9326 \\
.5680^{a}\end{array}$ & $\begin{array}{l}3.3302 \\
08336 c\end{array}$ & $\begin{array}{l}4.6916 \\
2.03 a\end{array}$ & \\
\hline$\delta_{\text {cons }}$ & $\begin{array}{l}2.5566^{a} \\
12.7557\end{array}$ & $\begin{array}{l}2.5466^{a} \\
12.3942\end{array}$ & $\begin{array}{l}2.5689^{a} \\
12.6071\end{array}$ & $\begin{array}{l}0.8336^{c} \\
1.7168\end{array}$ & ${ }_{7.7114}^{2.2403^{a}}$ & \\
\hline$\delta_{\text {trend }}$ & & & & $\begin{array}{l}0.0868^{a} \\
5.4467\end{array}$ & & $\begin{array}{l}0.1237^{a} \\
11.3779\end{array}$ \\
\hline Depreciation rate & & & & & & \\
\hline Year 1 & 0.0720 & 0.0727 & 0.0712 & 0.2849 & 0.1079 & 0.4792 \\
\hline Year 10 & & & & 0.1542 & 0.0990 & 0.2489 \\
\hline Year 20 & & & & 0.0711 & 0.0800 & 0.0820 \\
\hline Init. Price & & $\begin{array}{l}-0.0614 \\
-0.5419\end{array}$ & $\begin{array}{l}-0.0389 \\
-0.3629\end{array}$ & $\begin{array}{l}-0.0248 \\
-0.1411\end{array}$ & $\begin{array}{l}0.0446 \\
0.3259\end{array}$ & $\begin{array}{l}0.3305 \\
1.1547\end{array}$ \\
\hline Init. Area & & -0.0749 & -0.3250 & -0.5561 & -0.4325 & -1.7670 \\
\hline EU PBR & & & $\begin{array}{l}-0.8686 \\
-0.8865\end{array}$ & $\begin{array}{l}-0.865 \\
-1.4596\end{array}$ & $\begin{array}{l}-0.8604 \\
-0.6030\end{array}$ & $\begin{array}{l}-1.5910 \\
-1.4520\end{array}$ \\
\hline PBRs Applicant & & & $\begin{array}{c}-1.3054 \\
0.0490\end{array}$ & $\begin{array}{c}-1.2629 \\
0.0754\end{array}$ & $\begin{array}{l}-0.5831 \\
0.1938^{b}\end{array}$ & $\begin{array}{l}-0.7188 \\
0.4070^{b}\end{array}$ \\
\hline & & & 0.8814 & 0.8212 & 2.1799 & 2.3575 \\
\hline PBRs Competitors & & & $\begin{array}{c}-0.1016 \\
-1.3296\end{array}$ & $\begin{array}{c}-0.1981 \\
-1.4494\end{array}$ & $\begin{array}{l}-0.2149^{\circ} \\
-2.1364\end{array}$ & $\begin{array}{l}-0.4813^{\circ} \\
-2.2267\end{array}$ \\
\hline French & & & $\begin{array}{l}0.2541^{c} \\
1.8924\end{array}$ & $\begin{array}{c}0.4325^{c} \\
1.7322\end{array}$ & $\begin{array}{c}0.1514 \\
0.9036\end{array}$ & $\begin{array}{c}0.2828 \\
0.8446\end{array}$ \\
\hline Price change & & & & & 0.1300 & 0.2511 \\
\hline Area change & & & & & $4.0719^{a}$ & $3.1126^{b}$ \\
\hline vEU PBR & & & & & $-2.7919^{a}$ & $-2.4004^{a}$ \\
\hline New Rights App. & & & & & $\begin{array}{l}-5.7846 \\
0.2129^{a}\end{array}$ & $\begin{array}{l}-3.8587 \\
0.1886^{a}\end{array}$ \\
\hline Exit Applicant & & & & & $\begin{aligned} & 4.6128 \\
- & 0.3271^{a}\end{aligned}$ & $\begin{array}{c}4.0916 \\
-0.3612^{a}\end{array}$ \\
\hline & & & & & -10.2126 & -9.3720 \\
\hline New Rights Comp. & & & & & $\begin{array}{c}-0.0052^{c} \\
-1.7599\end{array}$ & $\begin{array}{l}-0.0108^{a} \\
-3.7185\end{array}$ \\
\hline Exit Competitors & & & & & $\begin{array}{l}0.0202^{a} \\
2.8501\end{array}$ & $0_{2.9116}^{0.0204^{a}}$ \\
\hline $\log \mathrm{L}$ & -1090.5848 & -1090.4201 & -1084.9893 & -1069.2444 & -1028.9050 & -999.5707 \\
\hline LR & 68.9954 & 0.3294 & 10.8616 & 31.4898 & 112.1687 & 139.3474 \\
\hline
\end{tabular}


Table 8 - Simulated Values (in constant 2005 euros)

\begin{tabular}{|c|c|c|c|c|c|c|}
\hline & Model 1 & Model 2 & Model 3 & Model 4 & Model 5 & Model 6 \\
\hline & \multicolumn{6}{|c|}{ Wheat } \\
\hline Mean & $4.6746 \mathrm{e}+03$ & $4.7274 \mathrm{e}+03$ & $4.8452 \mathrm{e}+03$ & $4.5682 \mathrm{e}+05$ & $6.2210 \mathrm{e}+03$ & $2.4443 \mathrm{e}+05$ \\
\hline $10 \%$ & $7.2585 \mathrm{e}+01$ & $6.9902 \mathrm{e}+01$ & $6.9283 \mathrm{e}+01$ & $2.2747 \mathrm{e}+02$ & $6.7458 \mathrm{e}+01$ & $1.7621 \mathrm{e}+02$ \\
\hline $25 \%$ & $3.6202 \mathrm{e}+02$ & $3.5386 \mathrm{e}+02$ & $3.5806 \mathrm{e}+02$ & $1.7894 \mathrm{e}+03$ & $3.8213 \mathrm{e}+02$ & $1.3831 \mathrm{e}+03$ \\
\hline Median & $1.3799 \mathrm{e}+03$ & $1.3661 \mathrm{e}+03$ & $1.3927 \mathrm{e}+03$ & $1.2493 \mathrm{e}+04$ & $1.5706 \mathrm{e}+03$ & $9.1450 \mathrm{e}+03$ \\
\hline $75 \%$ & $4.3955 \mathrm{e}+03$ & $4.4256 \mathrm{e}+03$ & $4.4991 \mathrm{e}+03$ & $7.8926 \mathrm{e}+04$ & $5.3385 \mathrm{e}+03$ & $5.2935 \mathrm{e}+04$ \\
\hline $90 \%$ & $1.1112 \mathrm{e}+04$ & $1.1323 \mathrm{e}+04$ & $1.1537 \mathrm{e}+04$ & $3.9913 \mathrm{e}+05$ & $1.4347 \mathrm{e}+04$ & $2.5217 \mathrm{e}+05$ \\
\hline $99 \%$ & $4.9295 \mathrm{e}+04$ & $5.0379 \mathrm{e}+04$ & $5.2149 \mathrm{e}+04$ & $6.4959 \mathrm{e}+06$ & $7.2260 \mathrm{e}+04$ & $3.5194 \mathrm{e}+06$ \\
\hline \multirow[t]{2}{*}{$99.9 \%$} & $1.4054 \mathrm{e}+05$ & $1.4658 \mathrm{e}+05$ & $1.4888 \mathrm{e}+05$ & $4.9514 \mathrm{e}+07$ & $2.2190 \mathrm{e}+05$ & $2.5685 \mathrm{e}+07$ \\
\hline & \multicolumn{6}{|c|}{ Maize } \\
\hline Mean & $1.8391 \mathrm{e}+03$ & $1.9231 \mathrm{e}+03$ & $1.9647 \mathrm{e}+03$ & $4.1582 \mathrm{e}+04$ & $2.2326 \mathrm{e}+03$ & $7.3600 \mathrm{e}+04$ \\
\hline $10 \%$ & $3.7619 \mathrm{e}+01$ & $3.5906 \mathrm{e}+01$ & $3.5672 \mathrm{e}+01$ & $1.0243 \mathrm{e}+02$ & $3.9378 \mathrm{e}+01$ & $1.4336 \mathrm{e}+02$ \\
\hline $25 \%$ & $1.8915 \mathrm{e}+02$ & $1.8542 \mathrm{e}+02$ & $1.8476 \mathrm{e}+02$ & $6.8023 \mathrm{e}+02$ & $2.0076 \mathrm{e}+02$ & $9.2284 \mathrm{e}+02$ \\
\hline Median & $6.6406 \mathrm{e}+02$ & $6.6784 \mathrm{e}+02$ & $6.6674 \mathrm{e}+02$ & $3.6572 \mathrm{e}+03$ & $7.3749 \mathrm{e}+02$ & $5.1915 \mathrm{e}+03$ \\
\hline $75 \%$ & $1.9729 \mathrm{e}+03$ & $2.0257 \mathrm{e}+03$ & $2.0362 \mathrm{e}+03$ & $1.7026 \mathrm{e}+04$ & $2.2732 \mathrm{e}+03$ & $2.5712 \mathrm{e}+04$ \\
\hline $90 \%$ & $4.6394 \mathrm{e}+03$ & $4.8427 \mathrm{e}+03$ & $4.9208 \mathrm{e}+03$ & $6.4487 \mathrm{e}+04$ & $5.5569 \mathrm{e}+03$ & $1.0389 \mathrm{e}+05$ \\
\hline $99 \%$ & $1.6720 \mathrm{e}+04$ & $1.7867 \mathrm{e}+04$ & $1.8615 \mathrm{e}+04$ & $6.1796 \mathrm{e}+05$ & $2.1586 \mathrm{e}+04$ & $1.1148 \mathrm{e}+06$ \\
\hline \multirow[t]{2}{*}{$99.9 \%$} & $3.9441 \mathrm{e}+04$ & $4.3076 \mathrm{e}+04$ & $4.5961 \mathrm{e}+04$ & $3.1943 \mathrm{e}+06$ & $5.5022 \mathrm{e}+04$ & $6.1186 \mathrm{e}+06$ \\
\hline & \multicolumn{6}{|c|}{ Sunflower } \\
\hline Mean & $2.3388 \mathrm{e}+03$ & $2.3070 \mathrm{e}+03$ & $2.1565 \mathrm{e}+03$ & $7.1239 \mathrm{e}+05$ & $3.4320 \mathrm{e}+03$ & $1.3920 \mathrm{e}+05$ \\
\hline $10 \%$ & $4.6152 \mathrm{e}+01$ & $4.6195 \mathrm{e}+01$ & $4.6380 \mathrm{e}+01$ & $2.2601 \mathrm{e}+02$ & 6.2051 & $2.0630 \mathrm{e}+02$ \\
\hline $25 \%$ & $2.2562 \mathrm{e}+02$ & $2.2016 \mathrm{e}+02$ & $2.1559 \mathrm{e}+02$ & $1.8019 \mathrm{e}+03$ & $2.8807 \mathrm{e}+02$ & $1.3119 \mathrm{e}+03$ \\
\hline Median & $8.0606 \mathrm{e}+02$ & $7.9226 \mathrm{e}+02$ & $7.6121 \mathrm{e}+02$ & $1.3362 \mathrm{e}+04$ & $1.0615 \mathrm{e}+03$ & $7.6519 \mathrm{e}+03$ \\
\hline $75 \%$ & $2.4375 \mathrm{e}+03$ & $2.3981 \mathrm{e}+03$ & $2.2812 \mathrm{e}+03$ & $9.1467 \mathrm{e}+04$ & $3.3319 \mathrm{e}+03$ & $4.0287 \mathrm{e}+04$ \\
\hline $90 \%$ & $5.8339 \mathrm{e}+03$ & $5.7606 \mathrm{e}+03$ & $5.4003 \mathrm{e}+03$ & $5.1474 \mathrm{e}+05$ & $8.3817 \mathrm{e}+03$ & $1.7556 \mathrm{e}+05$ \\
\hline $99 \%$ & $2.2067 \mathrm{e}+04$ & $2.1781 \mathrm{e}+04$ & $1.9966 \mathrm{e}+04$ & $9.7979 \mathrm{e}+06$ & $3.5206 \mathrm{e}+04$ & $2.1126 \mathrm{e}+06$ \\
\hline \multirow[t]{2}{*}{$99.9 \%$} & $5.3384 \mathrm{e}+04$ & $5.3003 \mathrm{e}+04$ & $4.8045 \mathrm{e}+04$ & $8.2577 \mathrm{e}+07$ & $9.3395 \mathrm{e}+04$ & $1.2860 \mathrm{e}+07$ \\
\hline & \multicolumn{6}{|c|}{ Rapeseed } \\
\hline Mean & $6321 \mathrm{e}+03$ & $2.5446 \mathrm{e}+03$ & $1.9584 \mathrm{e}+03$ & $6.5369 \mathrm{e}+03$ & $2.2197 \mathrm{e}+03$ & $5.2089 \mathrm{e}+04$ \\
\hline $10 \%$ & $8503 \mathrm{e}+01$ & $4.0552 \mathrm{e}+01$ & $4.0821 \mathrm{e}+01$ & $6.5750 \mathrm{e}+01$ & $3.6648 \mathrm{e}+01$ & $5.2202 \mathrm{e}+03$ \\
\hline $25 \%$ & $1.8199 \mathrm{e}+02$ & $2.0081 \mathrm{e}$ & $1.8458 \mathrm{e}+02$ & 3.2 & 1.6199 & $1.1028 \mathrm{e}+04$ \\
\hline Median & $6.1561 \mathrm{e}+02$ & $7.2771 \mathrm{e}+02$ & $6.3373 \mathrm{e}+02$ & $1.2957 \mathrm{e}+03$ & $5.6381 \mathrm{e}+02$ & $2.5069 \mathrm{e}+04$ \\
\hline $75 \%$ & $1.7496 \mathrm{e}+03$ & $2.2744 \mathrm{e}+03$ & $1.8655 \mathrm{e}+03$ & $4.4687 \mathrm{e}+03$ & $1.7906 \mathrm{e}+03$ & $5.7442 \mathrm{e}+04$ \\
\hline $90 \%$ & $4.0707 \mathrm{e}+03$ & $5.9607 \mathrm{e}+03$ & $4.6410 \mathrm{e}+03$ & $1.3166 \mathrm{e}+04$ & $5.0797 \mathrm{e}+03$ & $1.1868 \mathrm{e}+05$ \\
\hline $99 \%$ & $1.4729 \mathrm{e}+04$ & $2.8008 \mathrm{e}+04$ & $2.0301 \mathrm{e}+04$ & $8.6330 \mathrm{e}+04$ & $2.7148 \mathrm{e}+04$ & $4.0979 \mathrm{e}+05$ \\
\hline \multirow[t]{2}{*}{$99.9 \%$} & $3.4795 \mathrm{e}+04$ & $8.1418 \mathrm{e}+04$ & $5.6272 \mathrm{e}+04$ & $3.3590 \mathrm{e}+05$ & $7.0324 \mathrm{e}+04$ & $1.0305 \mathrm{e}+06$ \\
\hline & \multicolumn{6}{|c|}{ Peas } \\
\hline Mean & $5119 \mathrm{e}+03$ & $1.5444 \mathrm{e}+03$ & $1.4949 \mathrm{e}+03$ & $5.1575 \mathrm{e}+03$ & 2.0078 & $1.3129 \mathrm{e}+05$ \\
\hline $10 \%$ & $3051 \mathrm{e}+01$ & $4.9635 \mathrm{e}+01$ & $4.9220 \mathrm{e}+01$ & 9.2009 & 5.6028 & $2.2735 \mathrm{e}+02$ \\
\hline $25 \%$ & $2.0433 \mathrm{e}+02$ & $2.0094 \mathrm{e}+02$ & $1.9738 \mathrm{e}+02$ & $4.0938 \mathrm{e}+02$ & $2.2971 \mathrm{e}+02$ & $1.3934 \mathrm{e}+03$ \\
\hline Median & $6.3427 \mathrm{e}+02$ & $6.3899 \mathrm{e}+02$ & $6.2875 \mathrm{e}+02$ & $1.5096 \mathrm{e}+03$ & $7.5732 \mathrm{e}+02$ & $7.8356 \mathrm{e}+03$ \\
\hline $75 \%$ & $1.7206 \mathrm{e}+03$ & $1.7651 \mathrm{e}+03$ & $1.7220 \mathrm{e}+03$ & $4.7553 \mathrm{e}+03$ & $2.1872 \mathrm{e}+03$ & $4.0165 \mathrm{e}+04$ \\
\hline $90 \%$ & $3.7928 \mathrm{e}+03$ & $3.9132 \mathrm{e}+03$ & $3.7832 \mathrm{e}+03$ & $1.2274 \mathrm{e}+04$ & $4.9943 \mathrm{e}+03$ & $1.6880 \mathrm{e}+05$ \\
\hline $99 \%$ & $1.2437 \mathrm{e}+04$ & $1.2572 \mathrm{e}+04$ & $1.2100 \mathrm{e}+04$ & $5.5597 \mathrm{e}+04$ & $1.8043 \mathrm{e}+04$ & $1.9457 \mathrm{e}+06$ \\
\hline \multirow[t]{2}{*}{$99.9 \%$} & $2.6597 \mathrm{e}+04$ & $2.6452 \mathrm{e}+04$ & $2.5423 \mathrm{e}+04$ & $1.5744 \mathrm{e}+05$ & $4.2108 \mathrm{e}+04$ & $1.1804 \mathrm{e}+07$ \\
\hline & \multicolumn{6}{|c|}{ Potatoes } \\
\hline Mean & $4.3151 \mathrm{e}+03$ & $4.4260 \mathrm{e}+03$ & $4.2529 \mathrm{e}+03$ & $2.8086 \mathrm{e}+04$ & $7.6632 \mathrm{e}+04$ & $1.1818 \mathrm{e}+06$ \\
\hline $10 \%$ & $1.3433 \mathrm{e}+02$ & $1.3721 \mathrm{e}+02$ & $1.3578 \mathrm{e}+02$ & $3.1642 \mathrm{e}+02$ & $4.7009 \mathrm{e}+03$ & $1.2555 \mathrm{e}+03$ \\
\hline $25 \%$ & $4.9814 \mathrm{e}+02$ & $5.0804 \mathrm{e}+02$ & $4.9899 \mathrm{e}+02$ & $1.3931 \mathrm{e}+03$ & $1.2275 \mathrm{e}+04$ & $7.3909 \mathrm{e}+03$ \\
\hline Median & $1.7476 \mathrm{e}+03$ & $1.7796 \mathrm{e}+03$ & $1.7202 \mathrm{e}+03$ & $5.6866 \mathrm{e}+03$ & $3.1955 \mathrm{e}+04$ & $4.5203 \mathrm{e}+04$ \\
\hline $75 \%$ & $4.9011 \mathrm{e}+03$ & $5.0213 \mathrm{e}+03$ & $4.8315 \mathrm{e}+03$ & $2.0229 \mathrm{e}+04$ & $7.9310 \mathrm{e}+04$ & $2.5868 \mathrm{e}+05$ \\
\hline $90 \%$ & $1.0801 \mathrm{e}+04$ & $1.1052 \mathrm{e}+04$ & $1.0569 \mathrm{e}+04$ & $5.9243 \mathrm{e}+04$ & $1.7581 \mathrm{e}+05$ & $1.2150 \mathrm{e}+06$ \\
\hline $99 \%$ & $3.6203 \mathrm{e}+04$ & $3.7246 \mathrm{e}+04$ & $3.5562 \mathrm{e}+04$ & $3.6173 \mathrm{e}+05$ & $6.8403 \mathrm{e}+05$ & $1.7348 \mathrm{e}+07$ \\
\hline $99.9 \%$ & $8.3990 \mathrm{e}+04$ & $8.6656 \mathrm{e}+04$ & $8.3848 \mathrm{e}+04$ & $1.3236 \mathrm{e}+06$ & $1.8667 \mathrm{e}+06$ & $1.2102 \mathrm{e}+08$ \\
\hline
\end{tabular}

Concerning the impact of PBR-specific variables, the fact that the applicant is a French firm (variable French) implies that the initial rent is significantly higher 
ceteris paribus for maize, sunflower, and to a lesser extent for potatoes (in Model 3 and Model 4) but significantly lower for wheat (in Models 5 and 6) and rapeseed. The initial rent is neither higher nor lower for spring wheat compared to other varieties of wheat (variable Spring in Table 2). According to the size and significance of the coefficient of PBRs Applicant, the market power effect seems to prevail on the minor incremental effect for wheat (Model 6) and potatoes (Model 5 and Model 6). Conversely, the minor incremental effect seems to prevail on the market power effect for maize and sunflower, and in Model 3 and Model 4 for peas and rapeseed. PBRs Competitors significantly affects the initial rent only for potatoes (in Model 5 and Model 6). The negative coefficient is then consistent with what was expected. The $e x$ ante ambiguity about the effect of variables New Rights App. and Exit Applicant on the depreciation rate of the rent is resolved ex post by the estimation results. Indeed, in the case of maize rapeseed and potatoes, the gain in terms of a higher market power seems to be more important than the dilution effect, so that New Rights App. weakens the depreciation rate whereas Exit Applicant strengthens the depreciation rate. Estimation results for variables New Rights Competitors and Exit Competitors deserve more comments because they do not only explain the depreciation of the rent, but their coefficients are also key coefficients to test the potential impact of a removal of exemption rules that distinguish PBRs from patent.

\subsection{A test of the exemption rules}

We now turn to a discussion of the way we can test the impact of exemption rules. We focus on Model 6 that contains all the control variables because the LR tests show that the different groups of control variables significantly contribute to explain renewal decisions and, consequently, affect PBRs' values. Model 6 is preferred to Model 5 for all crops. Indeed, $\delta_{\text {trend }}$ is significant for all crops except rapeseed and constitutes the only difference between the two models.

The farmers' exemption rule allows farmers to self-produce seeds from their harvested crops for their own usage. For this exemption rule to affect the value of 
PBRs, it is required that the initial rent is sensitive ceteris paribus to the total acreage of land devoted to the crop. Indeed, a removal of the exemption rule is expected to induce a switch of farmers previously using farm-saved seeds to breeders' seeds. Consequently, if a proportion $x$ of seeds currently used for a crop are farmsaved seeds, removing farmers' exemption potentially implies a maximum increase by $100 *(x /(1-x)) \%$ of the market size for seeds of the crop. This is only an upper bound of the expected increase because farmers may prefer to switch to other crops rather than buying certified seeds of the initial crop. It is worthwhile stressing that the ceteris paribus clause plays a crucial role to correctly assess this effect. It is crucial to control for the price of the crop in order to distinguish between, on the one hand, an increase of the total acreage induced by an increase of the price of the crop and, on the other hand, an increase of the total acreage that occurs independently of an increase of the price of the crop. The model we have estimated allows for this distinction and is thus suitable for the test. Moreover, for farmers' exemption to matter, it is required that the initial rent is positively and significantly impacted by variations in the total acreage of the crop for an unchanged price of the crop. This precludes the case of wheat for which Table 2 reports a negative coefficient of the variable Init. Area, whatever the model considered as well as maize peas and potatoes for which the coefficient is not significant. Indeed, the coefficient of Init. Area directly yields the elasticity of the initial rent, and consequently of the value of PBRs, with respect to Init. Area. For the farmers' exemption to matter, it is thus required that this coefficient is significant. Another prerequisite to test the impact of a removal of farmers' exemption is that the share of farm-saved seeds for the crop is sufficiently high. This is not the case for maize and sunflower. Consequently, the focus is only on rapeseed to test the impact of farmers' exemption. Farmer's exemption seems to have no impact on all other crops. Table 9 presents detailed results on the distribution of the relative increase of the value of PBRs that would result from a removal of farmers' exemption for rapeseed. ${ }^{6}$ The first row of the bottom part of

\footnotetext{
${ }^{6}$ The corresponding change of values in thousand of 2005 constant euros are reported in smaller just below.
} 
the Table yields the simulated relative increase of the mean of values whereas the next rows report the simulated relative increase of the values according to the initial quantile of value. These simulations are obtained on the basis of the current share of farm-saved seeds in the total quantity of seeds of the corresponding crop in France that amounts to $30 \%$. The relative increase of the value of PBRs has been computed for each PBR in the dataset with a statutory life limit that was anterior to the end of the period studied. Indeed, we wanted to avoid having to rely on forecasts of the variables affecting the dynamics of the rent and thus the study has been restrained to cohorts for which the time path of these variables was completely observed. In average, a removal of farmers' exemption would generate an increase of $66.02 \%$ of the value of PBRs. This relative increase ranges from $59.95 \%$ for the $10 \%$ PBRs with the lowest initial values to almost twice more $(103.12 \%)$ for the $0.1 \%$ of PBRs with the highest initial values.

Table 9 - Farmers' privilege impact for rapeseed

\begin{tabular}{l|c} 
Share of Farm-saved seeds & $30 \%$ \\
\hline Mean & $66.02 \%$ \\
$10 \%$ & 6.89 \\
$25 \%$ & $59.95 \%$ \\
1.31 \\
Median & $61.65 \%$ \\
$75 \%$ & 64.39 \\
$90 \%$ & $4.49 \%$ \\
$99 \%$ & $69.20 \%$ \\
$99.9 \%$ & $73.76 \%$ \\
14.73 \\
\hline
\end{tabular}

Normal size numbers report the relative increase of the value of PBRs whereas small size numbers report the absolute increase of the value of PBRs in thousands of 2005 constant euros.

Research exemption allows breeders to freely use varieties created by competitors and protected by a PBR for developing new varieties. It originates in the generally accepted idea that plant variety creation is essentially an incremental innovation process. The removal of inventors' exemption is thus expected to slow down the 
pace of variety creation. For this exemption rule to affect the value of PBRs, it is not only required that the depreciation rate is increased when competitors are granted new PBRs and decreased when competitors withdraw their PBRs, but also that the depreciation accelerates when the variety protected by the PBR in interest is "downgraded". What is meant by "downgraded" greatly matters for the test. It actually means that varieties can be ranked unequivocally and that the rank of the PBR in interest is deteriorated to reflect the effect of ongoing innovation. Downgrading just implies a change of the rank of the PBR in interest, independently of an increase of the number of PBRs to be ranked. It is thus crucial, in order to correctly capture this phenomenon, to control for the number of total PBRs on varieties of the crop. In other words, downgrading a PBR in our model results from the simultaneous grant of a new competing PBR and the withdrawal of an old one. It is thus measured as the net effect of the variables New Rights Comp. and Exits Competitors on the depreciation rate of the rent. Inventors' exemption will be considered to affect the value of PBRs if and only if the following three effects are observed simultaneously : a significant and negative coefficient of New Rights Comp. (variety creation by competitors accelerates the depreciation of the PBR in interest), a significant and positive coefficient of Exists Competitors (the withdrawal of PBRs by competitors slows down the depreciation of the PBR in interest) and a negative net cumulated effect of New Rights Comp. and Exit Competitors (downgrading the PBR in interest accelerates its depreciation). We consider the net effect of these variables rather than the net effect of variables New Rights App. and Exits Applicant because our focus is on the effect of innovation by competitors. Indeed, new varieties created by the same applicant may be strategically designed to avoid a "cannibalization" of the rent of her previously granted PBRs. Notice that only Model 5 and Model 6 that allow for an effect of these variables on the depreciation rate are suitable for the test. Model 6 is preferred to Model 5 due to the significance of the coefficient associated with $\delta_{\text {trend }}$. Last but not least, although we report results for the six crops, we consider that having the three aforementioned conditions satisfied simultaneously makes sense to analyze research exemption only if hybrid 
varieties are the exception not the rule. Indeed, a hybrid variety is the offspring of distinctly different parent types which can be kept secret and it can hardly reproduce itself. Therefore, using hybrid varieties as germplasm to develop new incremental varieties does not make much sense. A significant impact of "downgrading" when hybrid varieties are common, like maize, has to be understood rather as a signal of an intense innovation race with different germplasm than as the result of incremental innovation from similar germplasm.

Table 10 - Threshold values for the distribution of the impact of a slower downgrading

\begin{tabular}{|c|c|c|c|c|c|c|}
\hline & Wheat & Maize & Sunflower & Rapeseed & Peas & Potatoes \\
\hline $1 \%$ & $\begin{array}{c}-1.34 \% \\
-2013\end{array}$ & $\begin{array}{c}-0.11 \% \\
-89\end{array}$ & $\begin{array}{l}-1.05 \% \\
-2859\end{array}$ & $\begin{array}{c}-1.56 \% \\
-761\end{array}$ & $\begin{array}{c}-0.93 \% \\
-741\end{array}$ & $\begin{array}{l}-2.13 \% \\
-16569\end{array}$ \\
\hline $5 \%$ & $\begin{array}{c}-1.05 \% \\
-1541\end{array}$ & $\underset{8}{0.01 \%}$ & $\begin{array}{l}-0.73 \% \\
-1841\end{array}$ & $\begin{array}{c}-1.35 \% \\
-654\end{array}$ & $\begin{array}{c}-0.47 \% \\
-369\end{array}$ & $\begin{array}{l}-1.73 \% \\
-12922\end{array}$ \\
\hline $10 \%$ & $\begin{array}{c}-0.91 \% \\
-1301\end{array}$ & $\begin{array}{c}0.09 \% \\
70\end{array}$ & $\begin{array}{l}-0.53 \% \\
-1300\end{array}$ & $-1.26 \%$ & $\begin{array}{c}-0.19 \% \\
-154\end{array}$ & $\begin{array}{l}-1.49 \% \\
-11312\end{array}$ \\
\hline Median & $\begin{array}{c}-0.36 \% \\
-486\end{array}$ & $\begin{array}{c}0.36 \% \\
269\end{array}$ & $\begin{array}{c}0.13 \% \\
290\end{array}$ & $-0.91 \%$ & $\begin{array}{c}0.88 \% \\
631\end{array}$ & $\begin{array}{l}-0.84 \% \\
-6145\end{array}$ \\
\hline $90 \%$ & $\begin{array}{l}0.24 \% \\
286\end{array}$ & $\begin{array}{c}0.64 \% \\
454\end{array}$ & $\begin{array}{c}0.82 \% \\
1731\end{array}$ & $\begin{array}{l}-0.57 \% \\
-265\end{array}$ & $\begin{array}{c}2.04 \% \\
1318\end{array}$ & $\begin{array}{l}-0.22 \% \\
-1526\end{array}$ \\
\hline $95 \%$ & $\begin{array}{l}0.41 \% \\
469\end{array}$ & $\begin{array}{c}0.74 \% \\
499\end{array}$ & $\begin{array}{l}1.00 \% \\
2026\end{array}$ & $\begin{array}{c}-0.46 \% \\
-212\end{array}$ & $\begin{array}{c}2.37 \% \\
1528\end{array}$ & $\begin{array}{l}-0.05 \% \\
333\end{array}$ \\
\hline $99 \%$ & $\begin{array}{l}0.84 \% \\
870\end{array}$ & $\begin{array}{c}1.26 \% \\
589\end{array}$ & $\begin{array}{c}1.39 \% \\
2632\end{array}$ & $\begin{array}{c}-0.26 \% \\
-119 \\
\end{array}$ & $\begin{array}{c}3.06 \% \\
1860 \\
\end{array}$ & $\begin{array}{c}0.31 \% \\
2084\end{array}$ \\
\hline
\end{tabular}

If we focus on estimated coefficients, the only crop that satisfies simultaneously the three conditions for inventors' exemption to matters for the value of PBRs is maize. However, as explained when introducing the test, the fact that almost all varieties of maize are hybrid casts some doubt on the ability to draw conclusions about the removal of research exemption from these results. Peas and sunflower could also satisfy the three conditions if the coefficient of the variable Exit Competitors was significant. None of the three other crops satisfy the three conditions if we just look at estimated coefficients. Nevertheless, what we are interested in is not whether each coefficient taken alone is significant but if "downgrading" is significant. This calls for a test of the total impact of "downgrading" on PBRs values. The total impact can be significant even if each coefficient is not, mainly because of the covariances 
between estimated coefficients. Therefore, we have conducted Monte Carlo simulations to assess the effect of "downgrading". We used one thousand draws from the joint multinormal distribution of the two coefficients. For each draw and each PBR, we have generated a decrease of variables New Rights Comp. and Exit Competitors that amounts to one percent of the PBRs in force within the same cohort at the corresponding age of the PBR. Indeed, it is expected that a removal of research exemption would refrain competitors to invent around the varieties already protected and would consequently alleviate the "downgrading" of existing PBRs. We have then constructed the empirical distribution of the change in PBRs values over all PBRs, and computed the expected change for each draw of the two parameters. The main quantiles and the mean of the empirical distribution over the different draws of parameters are reported in Table 10. On the one hand, simulation results confirm that a slowdown in the "downgrading" of PBRs is more likely to have a positive impact than a negative impact on the expected value of PBRs for maize and, to a lesser extent, for sunflower and peas. However hybrid varieties are very common for maize so that, as already outlined, we cannot draw conclusions as regards research exemption for this crop. On the other hand, a negative impact on their expected value is more likely for PBRs protecting wheat varieties, rapeseed varieties or potatoes varieties.

A possible explanation of the absence of a clear cut effect on the value of PBRs of research exemption is that each applicant actually targets a specific niche and develops new varieties within this niche but does not attempt to compete with other firms outside this niche. Thus, following the logic of horizontal differentiation, the value of PBRs is not affected by the grant of PBRs to competitors because the distance between PBRs of different applicants is sufficiently wide to substantially lessens the effects of competition. 


\section{Conclusion}

In order to assess whether farmers' exemption and inventors' exemption significantly affect the value of PBRs compared to what it would amount to in the absence of these exemption rules, a model of renewal decisions suitable for estimation on PBR micro-level data has been developed. The estimation of the model on French PBRs for six major crops over the last decades yields mitigated results as regards the importance of the two exemption rules.

No clear cut evidence of a detrimental impact of research exemption is found. The article thus argues against a strengthening of IPRs in the seed sector that would foster the ability of PBRs' holders to deter competitors from "inventing around" protected varieties. There is a risk to induce a surge in IPRs application without sizable incidence on the pace of technological progress, as it has been partly observed in other sectors characterized by cumulative innovation (see for instance Hall and Ziedonis, 2001, for the case of semiconductor following the strengthening of the US patent system in the 1980s). Farmers' exemption is found to have a significant impact on only one of the six crops studied. These results suggest that product differentiation is likely to alleviate the consequences of inventors' exemption whereas farmers' exemption has contrasted consequences depending on the crop in interest. As a conclusion, there is no strong empirical evidence that a PBRs regime to protect plant variety creation is really less efficient at generating private incentives to innovate compared to a patent regime. 


\section{References}

Alston, J. and Venner, R. The effects of the US plant variety protection act on wheat genetic improvement. Research Policy, 31(4):527-542, 2002. doi:10.1016/S00487333(01)00123-8.

Arrow, K. Economic welfare and the allocation of resources for invention. In The rate and direction of inventive activity: Economic and social factors, pages 609626. Princeton University Press, 1962. URL http://papers.nber.org/books/ univ62-1.

Barney, J. A. Study of patent mortality rates: Using statistical survival analysis to rate and value patent assets. AIPLA Quarterly Journal, 30(3):317, 2002.

Baudry, M. and Dumont, B. Patent renewals as options: improving the mechanism for weeding out lousy patents. Review of Industrial Organization, 28(1):41-62, 2006. doi:10.1007/s11151-006-0001-0.

Baudry, M. and Dumont, B. Valuing patents using renewal data: an inquiry into the feasability of an automated patent scoring method. Working Paper, 2012.

Bessen, J. The value of us patents by owner and patent characteristics. Research Policy, 37(5):932-945, 2008. doi:10.1016/j.respol.2008.02.005.

Bessen, J. Estimates of patent rents from firm market value. Research Policy, 38 (10):1604-1616, 2009. doi:10.1016/j.respol.2009.09.014.

Bloom, N. and Van Reenen, J. Patents, real options and firm performance. The Economic Journal, 112(478):C97-C116, 2002. doi:10.1111/1468-0297.00022.

Carew, R. and Devadoss, S. Quantifying the contribution of plant breeders' rights and transgenic varieties to canola yields: Evidence from manitoba. Canadian Journal of Agricultural Economics/Revue canadienne d'agroeconomie, 51(3):371395, 2003. doi:10.1111/j.1744-7976.2003.tb00181.x. 
Cornelli, F. and Schankerman, M. Patent renewals and r\&d incentives. The RAND Journal of Economics, 30(2):197-213, 1999. URL http://www.jstor. org/stable/2556077.

Dasgupta, P. and Stiglitz, J. Uncertainty, industrial structure, and the speed of r\&d. The Bell Journal of Economics, 11(1):1-28, 1980. URL http://www.jstor.org/ stable/3003398.

Diez, M. The impact of plant varieties rights on research: the case of spain. Food Policy, 27(2):171-183, 2002. doi:10.1016/S0306-9192(02)00010-6.

Evenson, R. Economic impacts of agricultural research and extension. In Handbook of agricultural economics, volume 1, pages 573-628. Elsevier, 2001. doi:10.1016/S1574-0072(01)10014-9.

Griliches, Z. Patent statistics as economic indicators: A survey. Journal of Economic Literature, 28(4):1661-1707, 1990. URL http://www .jstor.org/stable/ 2727442 .

Hall, B. H. and Ziedonis, R. H. The patent paradox revisited: An empirical study of patenting in the u.s. semiconductor industry, 1979-1995. The RAND Journal of Economics, 32(1):101-128, 2001.

Hall, B. H., Jaffe, A., and Trajtenberg, M. Market value and patent citations. RAND Journal of Economics, 36(1):16-38, Spring 2005. URL http://www.jstor.org/ stable/1593752.

Lanjouw, J., Pakes, A., and Putnam, J. How to count patents and value intellectual property: The uses of patent renewal and application data. The Journal of Industrial Economics, 46(4):405-432, 1998. URL http://www.jstor.org/stable/ 117497.

Lesser, W. Valuation of plant variety protection certificates. Review of Agricultural Economics, 16(2):231-238, 1994. URL http://www.jstor.org/stable/1349465. 
Lesser, W. An economic approach to identifying an effective sui generis system for plant variety protection under trips. Agribusiness, 16(1):96-114, 2000. URL http: //EconPapers.repec.org/RePEc:wly:agribz:v:16:y:2000:i:1:p:96-114.

Louwaars, N. P., Tripp, R., Eaton, D., Henson-Apollonio, V., Hu, R., Mendoza, M., Muhhuku, F., Pal, S., and Wekundah, J. Impacts of strengthened intellectual property rights regimes on the plant breeding industry in developing countries. Technical report, World Bank, 2005.

Pakes, A. Patents as options: Some estimates of the value of holding european patent stocks. Econometrica, 54(4):755-784, 1986. URL http://www.jstor. org/stable/1912835.

Pakes, A. and Schankerman, M. The rate of obsolescence of patents, research gestation lags, and the private rate of return to research resources. In $R \mathscr{G} D$, Patents, and Productivity, pages 73-88. University of Chicago Press, 1984.

Schankerman, M. How valuable is patent protection? estimates by technology field. the RAND Journal of Economics, 29(1):77-107, 1998. URL http://www . jstor. org/stable/2555817.

Schankerman, M. and Pakes, A. Valeur et obsolescence des brevets: une analyse des statistiques de renouvellement des brevets européens. Revue économique, 36(5): 917-941, 1985. URL http://www.jstor.org/stable/3501560.

Schankerman, M. and Pakes, A. Estimates of the value of patent rights in european countries during the post-1950 period. The Economic Journal, 96(384):1052-1076, 1986. URL http://www.jstor.org/stable/2233173.

Scotchmer, S. On the optimality of the patent renewal system. The RAND Journal of Economics, 30(2):181-196, 1999. URL http://www . jstor.org/stable/2556076.

Srinivasan, C. S. Exploring the feasibility of farmers' rights. Development Policy Review, 21(4):419-447, 2003. doi:10.1111/1467-7679.00218. 
Srinivasan, C. S. Modelling economic returns to plant variety protection in the uk. Bio-based and Applied Economics, 1(2):151-174, 2012. doi:10.13128/BAE-10557.

Thomson, R. The yield of plant variety protection. American Journal of Agricultural Economics, 97(3):762-785, 2015. doi:10.1093/ajae/aau099 